\title{
Simultaneous trace gas measurements using two Fourier transform spectrometers at Eureka, Canada during spring 2006, and comparisons with the ACE-FTS
}

\author{
D. Fu ${ }^{1}$, K. A. Walker ${ }^{1,2}$, R. L. Mittermeier ${ }^{3}$, K. Strong ${ }^{2}$, K. Sung ${ }^{2, * *}$, H. Fast ${ }^{3}$, P. F. Bernath ${ }^{1,4}$, C. D. Boone ${ }^{1}$, \\ W. H. Daffer ${ }^{5}$, P. Fogal ${ }^{2}$, F. Kolonjari ${ }^{2}$, P. Loewen ${ }^{2}$, G. L. Manney ${ }^{5,}$, O. Mikhailov ${ }^{2}$, and J. R. Drummond ${ }^{2}$ \\ ${ }^{1}$ Department of Chemistry, University of Waterloo, Waterloo, Ontario, Canada \\ ${ }^{2}$ Department of Physics, University of Toronto, Toronto, Ontario, Canada \\ ${ }^{3}$ Environment Canada, Toronto, Ontario, Canada \\ ${ }^{4}$ Department of Chemistry, University of York, Heslington, York, UK \\ ${ }^{5}$ Jet Propulsion Laboratory, California Institute of Technology, Pasadena, California, USA \\ *also at: New Mexico Institute of Mining and Technology, Socorro, New Mexico, USA \\ *** now at: Jet Propulsion Lab., California Institute of Technology, Pasadena, California, USA
}

Received: 5 December 2007 - Published in Atmos. Chem. Phys. Discuss.: 13 March 2008

Revised: 5 May 2011 - Accepted: 21 May 2011 - Published: 9 June 2011

\begin{abstract}
The 2006 Canadian Arctic ACE (Atmospheric Chemistry Experiment) Validation Campaign collected measurements at the Polar Environment Atmospheric Research Laboratory (PEARL, $86.42^{\circ} \mathrm{W}, 80.05^{\circ} \mathrm{N}, 610 \mathrm{~m}$ a.s.l.) at Eureka, Canada from 17 February to 31 March 2006. Two of the ten instruments involved in the campaign, both Fourier transform spectrometers (FTSs), were operated simultaneously, recording atmospheric solar absorption spectra. The first instrument was an ABB Bomem DA8 high-resolution infrared FTS. The second instrument was the Portable Atmospheric Research Interferometric Spectrometer for the Infrared (PARIS-IR), the ground-based version of the satelliteborne FTS on the ACE satellite (ACE-FTS). From the measurements collected by these two ground-based instruments, total column densities of seven stratospheric trace gases $\left(\mathrm{O}_{3}\right.$, $\mathrm{HCl}, \mathrm{ClONO}_{2}, \mathrm{HF}, \mathrm{HNO}_{3}, \mathrm{NO}_{2}$, and $\mathrm{NO}$ ) were retrieved using the optimal estimation method and these results were compared. Since the two instruments sampled the same portions of atmosphere by synchronizing observations during the campaign and used consistent retrieval parameters, the biases in retrieved columns from the two spectrometers represent the instrumental differences. Mean differences in total column densities of $\mathrm{O}_{3}, \mathrm{HCl}, \mathrm{ClONO}_{2}, \mathrm{HF}, \mathrm{HNO}_{3}$, and $\mathrm{NO}_{2}$ from the observations between PARIS-IR and the DA8 FTS are $2.8 \%,-3.2 \%,-4.3 \%,-1.5 \%,-1.9 \%$, and $-0.1 \%$, respectively. Partial column results from the ground-based
\end{abstract}

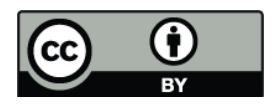

Correspondence to: K. A. Walker (kwalker@atmosp.physics.utoronto.ca) spectrometers were also compared with partial columns derived from ACE-FTS version 2.2 (including updates for $\mathrm{O}_{3}$ ) profiles. Mean differences in partial column densities of $\mathrm{O}_{3}$, $\mathrm{HCl}, \mathrm{ClONO}_{2}, \mathrm{HF}, \mathrm{HNO}_{3}, \mathrm{NO}_{2}$, and $\mathrm{NO}$ from the measurements between ACE-FTS and the DA8 FTS are $-5.9 \%$, $-8.5 \%,-11.8 \%,-0.9 \%,-6.6 \%,-21.6 \%$ and $-7.6 \%$ respectively. Mean differences in partial column densities of $\mathrm{O}_{3}, \mathrm{HCl}, \mathrm{ClONO}_{2}, \mathrm{HF}, \mathrm{HNO}_{3}, \mathrm{NO}_{2}$ from the measurements between ACE-FTS and the PARIS-IR are $-5.2 \%,-4.6 \%$, $-2.3 \%,-4.7 \%, 5.7 \%$ and $-11.9 \%$, respectively. This work provides further evidence of the reliability of ACE-FTS measurements from the first three years of on-orbit observations. Column densities of $\mathrm{O}_{3}, \mathrm{HCl}, \mathrm{ClONO}_{2}$, and $\mathrm{HNO}_{3}$ from the three FTSs were normalized with respect to HF and used to compare the time evolution of the chemical constituents in the atmosphere over Eureka during spring 2006.

\section{Introduction}

As part of the validation program for the Atmospheric Chemistry Experiment (ACE), a series of springtime measurement campaigns have been held in Eureka in northern Nunavut (Kerzenmacher et al., 2005; Walker et al., 2005; Manney et al., 2008; Sung et al., 2007; Fraser et al., 2008). The primary objective of these campaigns is to provide a multi-year, high-latitude data set for validating satellite data obtained under the perturbed conditions present in the springtime Arctic stratosphere.

Published by Copernicus Publications on behalf of the European Geosciences Union. 
ACE, also known as SCISAT, is a Canadian-led satellite mission for remote sensing of the Earth's atmosphere from a circular, low Earth orbit (altitude $650 \mathrm{~km}$, inclination $74^{\circ}$ ). This high inclination orbit provides global measurements over each season with a primary focus on the Arctic and Antarctic regions. An infrared Fourier transform spectrometer (ACE-FTS; Bernath et al., 2005) together with a dual, ultraviolet(UV)-visible-near-infrared spectrophotometer (Measurement of Aerosol Extinction in the Stratosphere and Troposphere Retrieved by Occultation (ACE-MAESTRO); McElroy et al., 2007) are the scientific instruments onboard the satellite. The primary goal of the ACE mission is understanding the chemistry and dynamics of ozone in the upper troposphere and stratosphere. Thus SCISAT measures the concentrations of more than 30 chemical constituents, including many that influence the distribution of stratospheric ozone (Bernath et al., 2005; Bernath, 2006).

Validating data products from satellite-borne infrared FTSs, such as ACE-FTS, can be challenging because of the wide range of atmospheric species that are measured. Ground-based FTSs, such as those that are part of the Network for the Detection of Atmospheric Composition Change (NDACC, http://www.ndsc.ncep.noaa.gov/), can contribute significantly to these efforts because they cover a similar spectral range with high spectral resolution (e.g., Vigouroux et al., 2007; Cortesi et al., 2007; Wetzel et al., 2007). Some information on the altitude distribution of the atmospheric trace gases can be retrieved from the shapes of the spectral lines obtained from these ground-based FTSs (e.g., Pougatchev et al., 1995; Rinsland et al., 1998). This allows partial column ${ }^{1}$ densities to be calculated from the groundbased measurements and it is these quantities that are compared with partial columns derived from the satellite observations.

As reported in other papers in this Special Issue, measurements from ground-based FTSs at 12 NDACC stations around the world have been employed in the ACE validation program (e.g. Clerbaux et al., 2008; De Mazière et al., 2008; Dupuy et al., 2009; Kerzenmacher et al., 2008; Mahieu et al., 2008; Strong et al., 2008; Wolff et al., 2008). This paper presents complementary work focusing on comparisons of ground- and satellite-based FTSs during Arctic springtime and on results for trace gas species that play an important role in ozone depletion processes that occur each spring in the polar vortex, including $\mathrm{O}_{3}$, the chlorine and nitrogen reservoir

\footnotetext{
${ }^{1}$ Throughout this paper, the term "total column" is used to indicate that the column amount was calculated from the full altitude range of the ground-based measurement (typically from the ground to $100 \mathrm{~km}$ ) whereas the term "partial column" is used for results obtained over a narrower altitude range. Depending on the type of ground-based measurement, the total column retrieved may be more sensitive to one region of the atmosphere than another (for example, $\mathrm{NO}_{2}$ retrievals from FTSs are only sensitive to the stratospheric part of the total column; Sussmann et al., 2005).
}

species $\left(\mathrm{HCl}, \mathrm{ClONO}_{2}\right.$ and $\left.\mathrm{HNO}_{3}\right), \mathrm{NO}_{\mathrm{x}}\left(\mathrm{NO}\right.$ and $\left.\mathrm{NO}_{2}\right)$, and a stratospheric tracer (HF) (e.g. Solomon, 1999).

The 2006 Canadian Arctic ACE Validation campaign was the third in this series of campaigns. It took place at the Polar Environment Atmospheric Research Laboratory (PEARL, $80.05^{\circ} \mathrm{N}, 86.42^{\circ} \mathrm{W}, 610 \mathrm{~m}$ a.s.l.) in Eureka, Nunavut, Canada, from 17 February to 31 March 2006. PEARL is located in a region of large stratospheric variability in the Arctic (Harvey and Hitchman, 1996), where there is a higher probability of making measurements both inside and outside the polar vortex. Ten scientific instruments were used during the campaign. These included PARIS-IR (Portable Atmospheric Research Interferometric Spectrometer for the Infrared, a terrestrial version of the ACE-FTS) (Fu et al., 2007), a high-resolution Bomem DA8 FTS that is part of NDACC (Donovan et al., 1997; Wiacek et al, 2006; Farahani et al., 2007), and balloon-borne ozonesondes (Davies et al., 2000; Tarasick et al., 2005). These instruments were used to derive total columns, partial columns, and vertical profiles for most of the ACE target species, as well as temperature and pressure.

Herein, we describe the 2006 campaign observations made by PARIS-IR and the Environment Canada (EC) DA8 FTS and discuss comparisons both between the ground-based instruments and with the ACE-FTS results. To compare the ground-based and satellite results, this work first investigates the differences between the retrieved columns obtained by PARIS-IR, which is a relatively "new" campaign instrument, and the DA8 FTS, which is a permanently installed instrument and has been making long term observations at PEARL since 1993. To focus on the differences in the vertical columns that arise from the instrument performance, PARIS-IR and the DA8 FTS were configured to measure atmospheric absorption spectra simultaneously. Details on the two ground-based FTSs and their observation strategies are illustrated in Sect. 2. The ground-based FTS retrieval method and measurement characterization are described in Sect. 3. The ACE-FTS measurements and retrievals are described in Sect. 4. In Sect. 5, total columns, partial columns and column ratios obtained from simultaneous atmospheric remote sensing measurements using PARIS-IR and the DA8 FTS at Eureka are reported. The results are used to compare measurements from PARIS-IR and the DA8 FTS, to investigate the quality of ACE occultation measurements, and to examine the consistency of the time evolution of the chemical constituents in the atmosphere over the Canadian high Arctic during spring 2006 obtained from these different data sets.

\section{Ground-based instrumentation and observations}

PARIS-IR is a portable FTS built for atmospheric remote sensing from the ground and airborne platforms such as highaltitude balloon gondolas. It was constructed as a terrestrial version of the ACE-FTS using a similar design and 
incorporating flight-spare optical components from the satellite instrument. Hence, PARIS-IR can achieve the same spectral resolution (maximum optical path difference (MOPD) of $\pm 25 \mathrm{~cm}$; maximum spectral resolution of $0.02 \mathrm{~cm}^{-1}$ ) and spectral coverage $\left(750-4400 \mathrm{~cm}^{-1}\right)$ as the ACE-FTS. Its maximum scanning speed is $2.5 \mathrm{~cm} \mathrm{~s}^{-1}$, which makes PARIS-IR capable of recording one double-sided interferogram at MOPD every $20 \mathrm{~s}$. A sandwich-type detector, which consists of mercury cadmium telluride (MCT) and indium antimonide (InSb) elements, is used in PARIS-IR to record spectra over its entire spectral range in a single scan (Fu et al., 2007). Although PARIS-IR was deployed at Eureka in 2004 and 2005, there were major instrument changes and improvements for the 2006 campaign. In the 2004 campaign, undesirable spikes in the interferograms recorded by PARISIR resulted in spectral channelling. The temperature control system in the metrology diode laser of PARIS-IR was unstable in the 2005 campaign resulting in degraded spectral resolution. In addition, PARIS-IR was realigned by the manufacturer in mid-2005 and its performance was improved.

An ABB Bomem DA8 FTS, a high-spectral-resolution (MOPD of $250 \mathrm{~cm}$; maximum spectral resolution of $0.002 \mathrm{~cm}^{-1}$ ) Michelson interferometer using dynamic alignment techniques, was installed at PEARL in February 1993 (Donovan et al., 1997; Farahani et al., 2007). Two independent detectors, MCT and InSb, are used to cover the spectral range from 700 to $5100 \mathrm{~cm}^{-1}$. DA8 FTS measurements are made using a sequence of nine optical filters to improve the Signal-to-Noise Ratio (SNR). For this study, we used spectra recorded with the following filters: $\mathrm{S} 1\left(3950-4300 \mathrm{~cm}^{-1}\right)$, S3 $\left(2400-3300 \mathrm{~cm}^{-1}\right)$, S5 $\left(1800-2050 \mathrm{~cm}^{-1}\right)$ and S6 (700$\left.1300 \mathrm{~cm}^{-1}\right)$. The MCT detector was used with filter S6 and for the rest of the filters, the spectra were recorded with the InSb detector.

A sun-tracking mirror system, permanently mounted on the roof of PEARL, was used to direct the solar beam into the FTS laboratory. To observe the atmosphere simultaneously using the two spectrometers, the solar beam (diameter $\sim 14 \mathrm{~cm}$ ) was split into two parts. One third of the solar beam was directed through the input window of PARIS-IR using a flat pickoff mirror. The rest of the solar beam was directed into the DA8 FTS. This measurement strategy differs from that used in the 2004 and 2005 Canadian Arctic ACE Validation Campaigns, when PARIS-IR and the DA8 FTS recorded spectra alternately. Making simultaneous measurements ensured that PARIS-IR and the DA8 FTS were sampling the same atmosphere and thus removed any differences in vertical columns due to temporal and spatial variations. The SNR and retrieved total column densities from several spectra recorded in shared beam mode and in whole beam mode were compared at the beginning of the campaign. Differences in total column densities between the two modes were found to be small, generally of the order of $1 \%$. PARISIR has a shorter acquisition time per spectrum (20 s) than the DA8 FTS (about 190 s). A single measurement from the DA8 FTS consists of four co-added spectra and requires about $13 \mathrm{~min}$ to collect. To further ensure simultaneity, all of the individual spectra $(\sim 40)$ collected by PARIS-IR during each 13-min DA8 measurement interval were co-added.

The campaign was carried out in two phases: the intensive and extended phases. The intensive phase took place from 17 February to 8 March 2006. During this time, measurements were made by all of the campaign instruments, including PARIS-IR and the DA8 FTS, when weather conditions allowed. The ground-based FTS measurements started on 21 February when the Sun became visible above the horizon. Also, balloon-borne ozonesondes were launched daily from the nearby Eureka Weather Station. After the intensive phase, PARIS-IR was shipped back to its home station, the Waterloo Atmospheric Observatory. The extended phase continued from 9 to 31 March 2006, with measurements by the DA8 FTS and several of the other instruments and weekly EC ozonesonde flights.

\section{Spectral analysis and retrievals for ground-based FTSs}

The spectra measured by PARIS-IR and the DA8 FTS were analyzed in a consistent manner using the same retrieval program, spectroscopic parameters, spectral ranges and a priori information. This was done in order to eliminate, as much as possible, any differences due to the retrieval process. The analyses were performed using SFIT2 (version 3.91) (Pougatchev et al., 1995; Rinsland et al., 1998). SFIT2 makes use of the Optimal Estimation Method (OEM) (Rodgers, 1990, 2000) to include a priori volume mixing ratio (VMR) profiles of atmospheric constituents as a function of altitude in the retrievals. The spectral ranges, called microwindows (MWs), used in the PARIS-IR and DA8 FTS retrievals are listed in Table 1. All of the spectroscopic line parameters and cross sections used in these retrievals are taken from the HIgh resolution TRANsmission molecular absorption database (HITRAN) 2004 (Rothman et al., 2004).

A model atmosphere is used in the SFIT2 program to simulate spectra. A forward model, named FSCATM (Gallery et al., 1983; Meier et al., 2004a), was applied to generate the model atmospheres using a priori VMR estimates, and pressure and temperature profiles. FSCATM carries out refractive ray tracing and a calculation of the air mass distribution, which is the number of molecules as a function of altitude, for each model atmosphere. The a priori estimates of VMR profiles were adapted from the a priori profiles constructed by A. Meier in 1998 for the NDACC station at Kiruna (Meier et al., 2004b). To adapt this set of VMR profiles for use with measurements from Eureka, the VMR profiles for $\mathrm{O}_{3}, \mathrm{HNO}_{3}, \mathrm{HCl}, \mathrm{HF}, \mathrm{ClONO}_{2}, \mathrm{NO}, \mathrm{NO}_{2}, \mathrm{HDO}$, $\mathrm{H}_{2} \mathrm{O}, \mathrm{CH}_{4}$, and $\mathrm{N}_{2} \mathrm{O}$, which are the target trace gases for this work or major interfering species in the spectral regions used in the retrievals, have been updated using results from: the 
Table 1. Species, spectral ranges of microwindows, interfering species, and filters used in ground-based observations.

\begin{tabular}{|c|c|c|c|c|}
\hline Species & $\mathrm{MW}^{\mathrm{a}}$ & Spectral Range $\left(\mathrm{cm}^{-1}\right)$ & Interfering species & Filter $^{b}$ \\
\hline \multirow{5}{*}{$\mathrm{O}_{3}$} & \multirow{4}{*}{$1120^{\mathrm{c}}$} & $1104.78-1105.08$ & $\mathrm{CH}_{3} \mathrm{D}, \mathrm{CHF}_{2} \mathrm{Cl}, \mathrm{CCl}_{2} \mathrm{~F}_{2}, \mathrm{H}_{2} \mathrm{CO}_{2}, \mathrm{HDO},{ }^{16} \mathrm{O}^{16} \mathrm{O}^{18} \mathrm{O}$ & \multirow{4}{*}{ S6 } \\
\hline & & $1119.73-1119.95$ & $\mathrm{CHF}_{2} \mathrm{Cl}, \mathrm{N}_{2} \mathrm{O},{ }^{16} \mathrm{O}^{16} \mathrm{O}^{18} \mathrm{O}$ & \\
\hline & & $1121.67-1122.03$ & ${ }^{16} \mathrm{O}^{16} \mathrm{O}^{18} \mathrm{O}, \mathrm{H}_{2} \mathrm{CO}_{2}, \mathrm{CHF}_{2} \mathrm{Cl}, \mathrm{N}_{2} \mathrm{O}, \mathrm{H}_{2} \mathrm{O}$ & \\
\hline & & $1122.84-1123.06$ & ${ }^{16} \mathrm{O}^{16} \mathrm{O}^{18} \mathrm{O}, \mathrm{H}_{2} \mathrm{CO}_{2}, \mathrm{CHF}_{2} \mathrm{Cl}, \mathrm{CH}_{3} \mathrm{D}, \mathrm{CH}_{4}, \mathrm{H}_{2} \mathrm{O}$ & \\
\hline & 2775 & $2775.68-2775.88$ & $\mathrm{HCl}, \mathrm{N}_{2} \mathrm{O}, \mathrm{CH}_{4}$ & S3 \\
\hline \multirow{2}{*}{$\mathrm{HNO}_{3}$} & 868 & $867.00-869.20$ & $\mathrm{H}_{2} \mathrm{O}, \mathrm{OCS}, \mathrm{NH}_{3}, \mathrm{CO}_{2}$ & S6 \\
\hline & 872 & $871.80-874.00$ & $\mathrm{H}_{2} \mathrm{O}, \mathrm{OCS}, \mathrm{NH}_{3}, \mathrm{CO}_{2}, \mathrm{C}_{2} \mathrm{H}_{4}, \mathrm{CCl}_{2} \mathrm{~F}_{2}$ & S6 \\
\hline $\mathrm{ClONO}_{2}$ & 780 & $779.85-780.45$ & $\mathrm{CO}_{2}, \mathrm{O}_{3}, \mathrm{HNO}_{3}, \mathrm{CCl}_{4}$ & S6 \\
\hline $\mathrm{HF}$ & 4038 & $4038.78-4039.10$ & $\mathrm{H}_{2} \mathrm{O}, \mathrm{CH}_{4}, \mathrm{HDO}$ & S1 \\
\hline \multirow{2}{*}{$\mathrm{HCl}$} & \multirow{2}{*}{$2725^{\mathrm{c}}$} & $2727.72-2727.84$ & $\mathrm{O}_{3}, \mathrm{CH}_{4}, \mathrm{HDO}, \mathrm{CO}_{2}$ & \multirow{2}{*}{ S3 } \\
\hline & & $2775.68-2775.88$ & $\mathrm{O}_{3}, \mathrm{CH}_{4}, \mathrm{~N}_{2} \mathrm{O}$ & \\
\hline $\mathrm{NO}^{\mathrm{d}}$ & 1903 & $1902.85-1903.35$ & $\mathrm{CO}_{2}, \mathrm{~N}_{2} \mathrm{O}, \mathrm{H}_{2} \mathrm{O}, \mathrm{OCS}, \mathrm{O}_{3}$ & S5 \\
\hline $\mathrm{NO}_{2}$ & 2914 & $2914.60-2914.70$ & $\mathrm{CH}_{4}, \mathrm{OCS}, \mathrm{CH}_{3} \mathrm{D}$ & S3 \\
\hline
\end{tabular}

\footnotetext{
a Microwindow region.

${ }^{\mathrm{b}}$ Filters were placed in front of the entrance aperture of the DA8 FTS to improve the SNR of the measurements.

See text for the spectral ranges of filters used in observations.

${ }^{\mathrm{c}}$ Several spectral ranges from individual spectra were fit simultaneously in the retrievals.

$\mathrm{d}$ PARIS-IR has no results for NO from the 2006 Canadian Arctic ACE Validation Campaign.
}

HALogen Occultation Experiment (HALOE) v. 19 data set between 1991 to 2005 (Russell et al., 1994; Grooß and Russell, 2005 and references therein), the 2002-2004 Michelson Interferometer for Passive Atmospheric Sounding (MIPAS) version 3.0 profiles produced with the Institut für Meteorologie und Klimaforschung scientific processor (Höpfner et al., 2006), the Stratospheric Processes And their Role in Climate 2000 climatology (SPARC2000) (Randel et al., 2002), and Eureka ozonesonde archive (Tarasick et al., 2005). The procedure used to update the VMR profiles is presented in detail in Sung et al., 2011. Pressure and temperature profiles were produced using data from three sources: the daily radiosondes from the Eureka Weather Station (launched daily at 11:15 and 23:15 UT), the National Centers for Environmental Prediction (NCEP)/National Center for Atmospheric Research (NCAR) analyses provided by the NASA Goddard Space Flight Centre automailer (obtained from the Goddard Automailer science@ hyperion.gsfc.nasa.gov) (McPherson et al., 1979; Kalnay et al., 1996), and the Mass-SpectrometerIncoherent-Scatter model (MSIS-2000) (Picone et al., 2002). From the surface to about $38 \mathrm{~km}$, the radiosonde measurements were used. Above that, the NCEP/NCAR analyses extend the profile from 38 to $50 \mathrm{~km}$ and the output from MSIS was used from 50 to $100 \mathrm{~km}$.

Instrument parameters, including the apodization and instrument lineshape functions, are required to simulate the absorption spectra used in the SFIT2 retrieval process. This is the area where the retrievals differed for the two FTSs. For the apodization function, the DA8 FTS used a Hamming function and PARIS-IR used a boxcar function. In earlier comparisons, it was demonstrated that it is necessary to have a well-characterized instrument line shape (ILS) in order to retrieve accurate total columns of stratospheric gases from PARIS-IR spectra (Wunch et al., 2007). In this current work, we used the LINEFIT program (Hase et al., 1999, version 11) to retrieve ILS information for the two FTSs from $\mathrm{N}_{2} \mathrm{O}$ features between 2400 and $2800 \mathrm{~cm}^{-1}$. These spectra were measured using a blackbody source and a $10-\mathrm{cm}-\mathrm{long}, 5.0-\mathrm{cm}-$ diameter cell that was filled with $7.5 \mathrm{hPa}$ of $\mathrm{N}_{2} \mathrm{O}$. The ILS results obtained were consistent with earlier measurements for the DA8 FTS and PARIS-IR (Wunch et al., 2007; Sung et al., 2007). The ILS parameters obtained from the cell measurements were used as the a priori values for the SFIT2 Emperical Apodization Function (EAP). The EAP is defined as a polynomial and SFIT2 allows for the subsequent retrieval of the polynomial coefficients as part of the state vector. We chose to retrieve third-order polynomial coefficients and a first-order polynomial coefficient for PARIS-IR and the DA8 FTS, respectively.

A 29-layer grid was used to retrieve profiles from the PARIS-IR and DA8 FTS spectra. In addition to the profiles, integrated vertical column densities are produced for each of the layers. These were used to calculate the total column densities and partial column densities used in this work. The fitting residuals from the SFIT2 retrievals were used to evaluate the quality of the results for the DA8 FTS and PARIS-IR. Using the data from the entire campaign, the mean and the $1 \sigma$ standard deviation of the root mean square (RMS) fitting 
Table 2. Degrees of freedom for signal and uncertainties in the retrievals of total vertical column densities obtained from measurements by the DA8 FTS and PARIS-IR.

\begin{tabular}{|c|c|c|c|c|c|c|c|c|c|c|c|}
\hline \multirow{2}{*}{ Species } & \multirow{2}{*}{$\mathrm{MW}^{\mathrm{a}}$} & \multicolumn{2}{|c|}{ Smoothing Error (\%) } & \multicolumn{2}{|c|}{ Retrieval Noise Error (\%) } & \multicolumn{2}{|c|}{ Model Parameter Error (\%) } & \multicolumn{2}{|c|}{ Total Error ${ }^{\mathrm{b}}(\%)$} & \multicolumn{2}{|c|}{ Degrees of Freedom } \\
\hline & & PAR $^{\mathrm{c}}$ & $\mathrm{DA} 8^{\mathrm{d}}$ & PAR & DA8 & PAR & DA8 & PAR & DA8 & PAR & DA8 \\
\hline \multirow[b]{2}{*}{$\mathrm{O}_{3}$} & 1120 & 7.9 & 5.4 & 2.9 & 2.5 & 0.5 & 0.3 & 8.4 & 6.0 & 3.6 & 4.2 \\
\hline & 2775 & 12.3 & 8.7 & 0.4 & 3.7 & 0.5 & 0.2 & 12.3 & 9.5 & 2.2 & 2.5 \\
\hline \multirow{2}{*}{$\mathrm{HNO}_{3}$} & 868 & 14.7 & 13.5 & 1.5 & 2.9 & 0.2 & 0.1 & 14.8 & 13.8 & 1.5 & 1.7 \\
\hline & 872 & 14.5 & 13.7 & 1.5 & 2.9 & 0.3 & 0.1 & 14.6 & 14.0 & 1.6 & 1.9 \\
\hline $\mathrm{ClONO}_{2}$ & 780 & 16.1 & 14.2 & 3.0 & 2.7 & 0.1 & 0.1 & 16.4 & 14.5 & 1.0 & 0.9 \\
\hline $\mathrm{HF}$ & 4038 & 6.8 & 5.5 & 1.3 & 2.5 & 0.2 & 0.1 & 6.9 & 6.0 & 1.7 & 1.7 \\
\hline $\mathrm{HCl}$ & 2725 & 7.5 & 7.4 & 0.8 & 2.7 & 0.3 & 0.1 & 7.6 & 7.9 & 1.7 & 1.7 \\
\hline NO & 1903 & N/A & 10.9 & N/A & 3.9 & N/A & 0.1 & N/A & 11.6 & N/A & 1.2 \\
\hline $\mathrm{NO}_{2}$ & 2914 & 25.1 & 22.7 & 2.8 & 3.7 & 0.1 & 0.1 & 25.3 & 23.0 & 1.7 & 1.9 \\
\hline
\end{tabular}

a See Table 1 for spectral ranges of microwindows.

$\mathrm{b}$ Total Error $=\sqrt{(\text { Smoothing Error })^{2}+(\text { Retrieval Noise Error })^{2}+(\text { Model Parameter Error })^{2}}$

c PARIS-IR.

d DA8 FTS.

residual were calculated for each MW and each FTS. Only those retrievals whose RMS fitting residuals were within one standard deviation of the mean were included in this study. For the DA8, this technique excluded at most 3-4 measurements out of $\sim 60$ recorded for each filter band during the campaign.

OEM, the method used in the SFIT2 spectral retrieval program, provides a method to compute the major uncertainties in the retrievals of vertical columns such as smoothing error, retrieval noise error and model parameter error (Rodgers, 2000; Rodgers and Connor, 2003). Smoothing error, also known as null space error in the Rodgers OEM formalism, mainly arises from the limited altitude resolution of the observing system (Rodgers, 1990, 2000). Retrieval noise error is due to measurement noise in the spectra. The forward model parameters such as spectral background, slope and instrumental line shape also generate uncertainties in the retrievals and these contributions are grouped together as model parameter error. Table 2 summarizes these errors in the total column densities obtained from the PARIS-IR and DA8 FTS observations and the root-sum-square of these errors was used to provide a total error estimate.

The spectral resolution of a measurement affects the amount of vertical information obtained from the spectral line shape of a measured species (Rodgers, 2000). With higher spectral resolution, more precise vertical information can be obtained. As shown in Table 2, the results from the DA8 FTS typically have higher values of Degrees Of Freedom for Signal (DOFS), which are the number of independent quantities retrieved from the observations, than those from PARIS-IR since the DA8 FTS has a spectral resolution 10 times higher than that of PARIS-IR. The DOFS can be improved by choosing high quality microwindows, i.e. spectral segments which contain many absorption lines of the investigated species with few (and ideally weak) absorption fea- tures from interfering species. The microwindows used in this work have generally improved the retrievals of $\mathrm{O}_{3}$ and $\mathrm{HCl}$ compared to those carried out in an instrument comparison campaign at University of Toronto (Wunch et al., 2007) in terms of DOFS.

According to Rodgers OEM theory, the averaging kernel is the derivative of a derived vector with respect to the true state vector, i.e., when this derivative is small (nearly 0 ) all of the information comes from the a priori and when it is large (near 1) then the information in the retrieval comes mainly from the measured spectra (Rodgers, 1990, 2000). The typical total column averaging kernels of the seven species investigated in this study are shown in Fig. 1. For all seven species, the retrievals show good performance since the averaging kernel values are close to 1 in the altitude ranges where most of the molecules are located. For example, the averaging kernel values from the $\mathrm{O}_{3}$ retrievals using spectral segments near $1120 \mathrm{~cm}^{-1}$ (MW1120 listed in Table 1) are close to 1 from 10 to $60 \mathrm{~km}$ for both FTSs. More than $80 \%$ of the total ozone resides in the altitude range from 10 to $60 \mathrm{~km}$.

\section{ACE-FTS satellite observations and analyses}

The ACE-FTS instrument performs up to 30 solar occultation measurements each day. Its spectral resolution $\left(0.02 \mathrm{~cm}^{-1}\right)$ and spectral range $\left(750-4400 \mathrm{~cm}^{-1}\right)$ match those of PARISIR. The ACE-FTS instrument records one measurement every $2 \mathrm{~s}$. The result of this sampling rate is that the typical vertical spacing of measurements within an occultation is 3$4 \mathrm{~km}$, neglecting the effects of refraction that compress the spacing at low altitudes. The actual vertical resolution of the ACE-FTS measurements is limited to about 3-4 km, due to the extent of the instrument field-of-view $(1.25 \mathrm{mrad})$ and the orbit altitude of the satellite $(650 \mathrm{~km})$. 

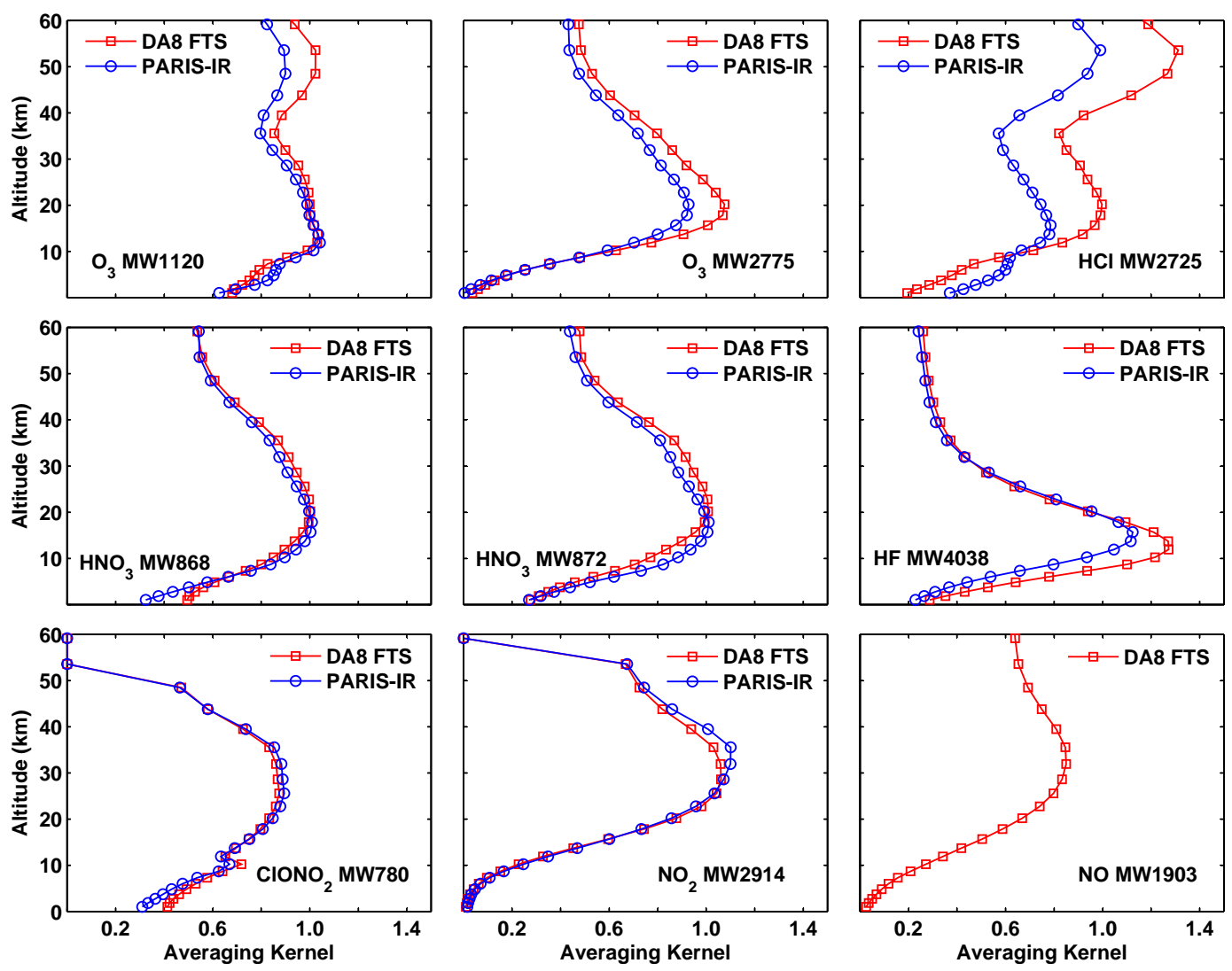

Fig. 1. Total column averaging kernels for PARIS-IR (blue circles) and the DA8 FTS (red squares) for 2006 Canadian Arctic ACE Validation Campaign.

The spectra measured by the ACE-FTS are analysed using a nonlinear least squares global fitting approach to obtain VMR profiles of trace gases in the Earth's atmosphere, along with pressure and temperature profiles (Boone et al., 2005). The retrieved profiles have a vertical resolution of $3-4 \mathrm{~km}$ and extend from the cloud tops (or $5 \mathrm{~km}$ under clear conditions) to about $100 \mathrm{~km}$. The current ACE-FTS data set, version 2.2 with updates for $\mathrm{O}_{3}, \mathrm{~N}_{2} \mathrm{O}_{5}$, and $\mathrm{HDO}$, contains VMR profiles for more than 30 atmospheric constituents. Validation results for the primary molecules measured with ACE can be found in this Special Issue (for example, the $\mathrm{O}_{3}$ validation paper by Dupuy et al., 2009). Partial column densities were calculated using atmospheric densities derived from the ACE-FTS measurements. Uncertainties in the partial column densities were calculated using the statistical fitting errors reported for the ACE-FTS VMR profiles.

During the campaign, ACE-FTS made thirteen occultation measurements within $500 \mathrm{~km}$ of PEARL. The location for each ACE occultation is given as the latitude, longitude and time of the $30-\mathrm{km}$ tangent point (calculated geometrically), and it is this value that was used in determining coincidences between observations. The ACE satellite measurements were made between 22 February and 13 March 2006.

\section{Results and discussion}

The spectra recorded with PARIS-IR, the DA8 FTS, and ACE-FTS during the campaign were analyzed using the methods described in Sects. 3 and 4. The results for seven primarily stratospheric trace gases $\left(\mathrm{O}_{3}, \mathrm{HNO}_{3}, \mathrm{HCl}\right.$, $\mathrm{ClONO}_{2}, \mathrm{NO}_{2}, \mathrm{NO}$, and $\mathrm{HF}$ ) are discussed here. In Sect. 5.1, comparisons of results between PARIS-IR and the DA8 FTS are described. In Sect. 5.2, results from the ground-based observations are compared to the ACE-FTS occultation measurements. Finally, in Sect. 5.3, results from the three FTSs will be used to compare the time evolution of chemical constituents in the atmosphere over the Canadian high Arctic during spring 2006, as seen by the different instruments. In these sections, total column and partial column densities will be used. The altitude range used for the partial columns was chosen to match the common range covered by all of the ACE-FTS measurements.

When comparing satellite and ground-based measurements, pairs of collocated measurements are identified using criteria based on the difference in distance and time between the measurements. Typically, the distance between the observatory housing the instrument and the tangent point of a specific altitude in the satellite profile is used to determine 
the spatial coincidence. For high-latitude stations where the solar elevation is relatively small, the location of the observatory does not necessarily give a good estimate of the location of the measured airmass because of the long slant path through the atmosphere. The point at which the observation slant path intersects with the atmospheric layer where the measurement is most sensitive can be located up to several hundred km away from the observatory. To better understand the region of the atmosphere that is being sounded in the DA8 FTS and PARIS-IR observations during the campaign, we have used a geometric calculation to estimate the ground locations of several altitudes along the slant path of the solar radiation. Refraction effects have been neglected. In the calculation, the distance between the observatory and the ground location is calculated using the solar zenith angle and the hour angle (the difference between the measurement local solar time and solar noon). Then, these are used with the location of PEARL and the haversine equation (Sinnott, 1984) to determine the latitude and longitude of the ground location. This method was used to estimate the ground locations of the $18-\mathrm{km}$ altitude point in the PARIS-IR and DA8 FTS measurements on 4 March 2006 and these locations are shown in Fig. 2. This altitude was chosen because it is near the peak in number density for $\mathrm{O}_{3}, \mathrm{HCl}, \mathrm{HNO}_{3}$, and other species of interest in this study during polar spring. Also, in this figure, the tangent point locations of the ACE-FTS occultations on 4 and 5 March are shown. They were within $100 \mathrm{~km}$ of the PEARL facility. However, the distance between the air mass sampled by the ground-based FTSs and that measured by ACE-FTS was of the order of $\sim 440-500 \mathrm{~km}$.

In addition to time and distance, an additional coincidence criterion is often needed when comparing measurements made at high latitudes: this is the location of the observations relative to the polar vortex. The meteorological conditions near Eureka and the location of the polar vortex during the 2006 campaign have been investigated by Manney et al. (2008). They used satellite results together with meteorological analyses to study the Arctic vortex, temperature and trace gas evolution over Eureka during the 2003-2004, 2004-2005 and 2005-2006 winter/spring periods. The 2005-2006 winter had a very strong, prolonged major "stratospheric sudden warming" (SSW) beginning in early to mid-January 2006 that ended in the mid- to late February 2006. After the SSW, a pole-centred strong vortex redeveloped quickly in the lower mesosphere. Throughout the campaign, the vortex was recovering and strengthening in the upper stratosphere. In the lower stratosphere, the vortex did not recover significantly from the SSW so it was fairly weak and poorly defined during the 2006 campaign. In the following, the locations of the satellite and ground-based measurements with respect to the vortex will be discussed in terms of scaled Potential Vorticity. sPV is the scaled (Dunkerton and Delisi, 1986; Manney et al., 1994) Rossby-Ertel potential vorticity (PV), which can be used to describe the intensity and geographical extent of the polar

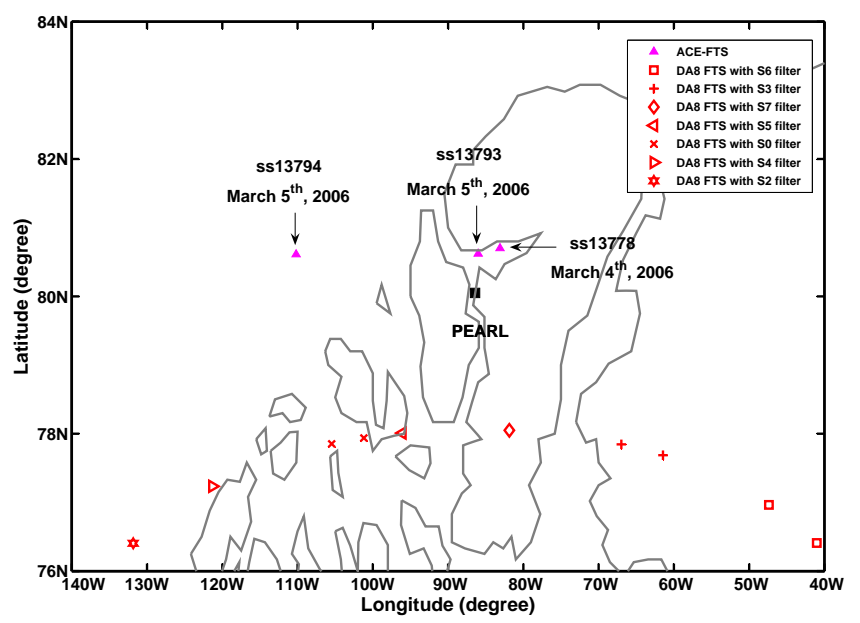

Fig. 2. Locations of simultaneous PARIS-IR and DA8 FTS measurements taken on 4 March 2006. Each measurement location is indicated using the ground location of the $18 \mathrm{~km}$ altitude in the FTS slant path (calculated geometrically) and is labelled with a red symbol. The shape of red symbol indicates the optical filter used for the DA8 FTS measurement. During each DA8 FTS measurement, PARIS-IR recorded the entire spectral region from 750 to $4400 \mathrm{~cm}^{-1}$. In addition, the tangent point locations of the ACE-FTS occultations made on 4 and 5 March 2006 are indicated. Location of PEARL is shown with a black solid square.

vortex. In the stratosphere, the vortex edge region is typically at $\mathrm{SPV}$ values of about 1.2 to $1.6 \times 10^{-4} \mathrm{~s}^{-1}$. The $\mathrm{sPV}$ values at altitudes along the measurement slant paths will be used to evaluate if the campaign observations were made inside, outside or on the edge of the polar vortex.

\subsection{Comparisons between PARIS-IR and the DA8 FTS}

Atmospheric solar absorption measurements were recorded simultaneously using PARIS-IR and the DA8 FTS on eight days during the intensive phase of the 2006 Canadian Arctic ACE Validation Campaign. These observations started on 21 February 2006, the day when the Sun was first seen above the horizon at PEARL. In the first week of the campaign, the measurements were limited because the Sun is only visible for a short period of time around noon, and that is further limited by topography and cloud. The length of each day increases rapidly at the beginning of the campaign (increasing from $\sim 2 \mathrm{~h}$ on 21 February to $\sim 6 \mathrm{~h}$ on 28 February, values calculated from the sunrise and sunset times provided by the Astronomical Application Department of U.S. Naval Observatory; http://aa.usno.navy.mil/). Often the measurements on the first days have large fitting residuals and thus very few are included in the comparisons. It should also be noted that the solar zenith angles for the measurements between 21 and 26 February range between $\sim 89$ and $90^{\circ}$. The weather conditions were poor during the middle of the intensive phase: no ground-based FTS measurements were made 


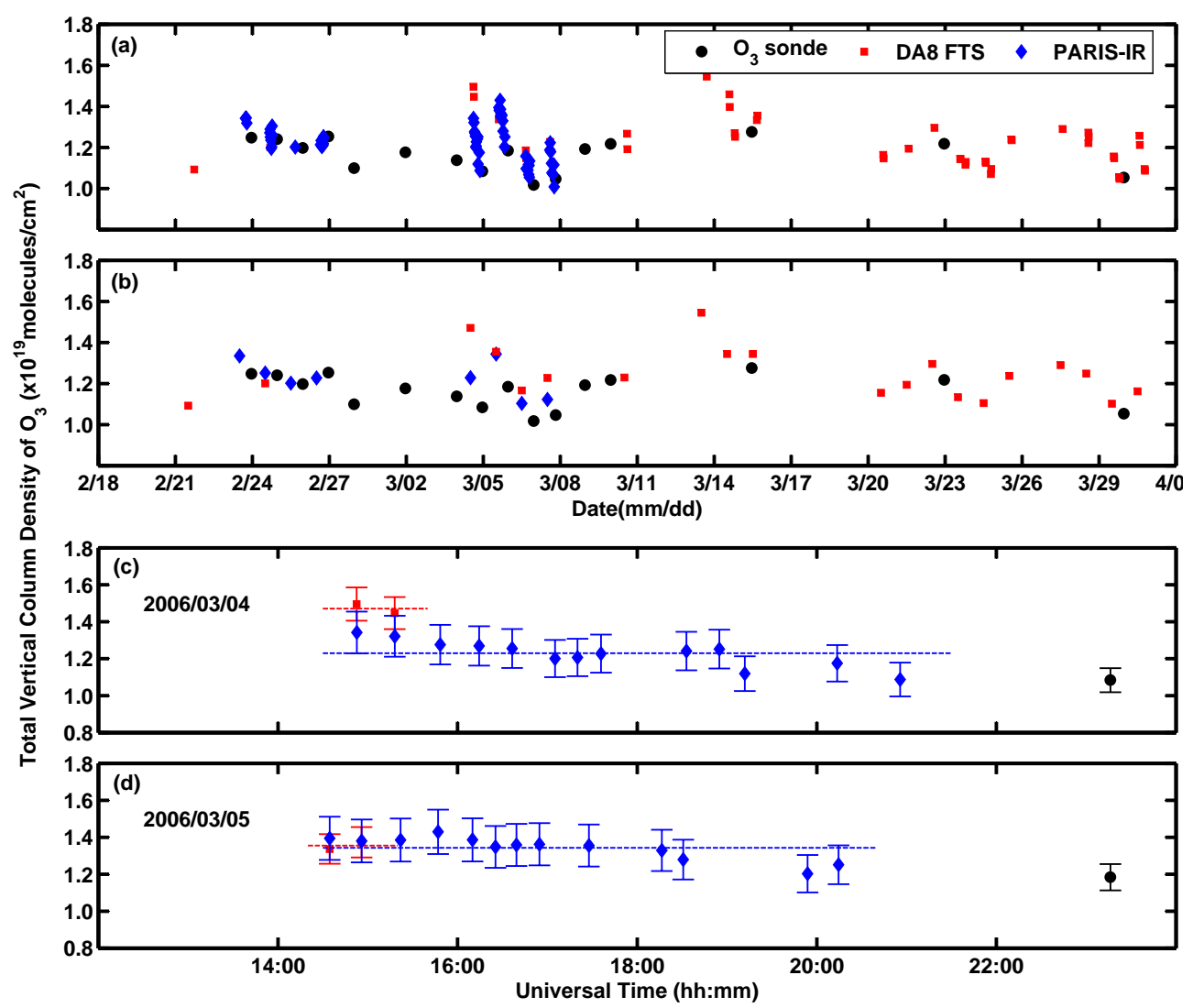

Fig. 3. $\mathrm{O}_{3}$ total vertical column densities obtained from the spectra near MW $1120 \mathrm{~cm}^{-1}$ (MW1120) recorded using PARIS-IR (blue diamonds) and the DA8 FTS (red squares) during the 2006 Canadian Arctic ACE Validation Campaign are shown together with total columns calculated from ozonesonde measurements (black circles). Panels (a) and (b) show the individual and the daily mean column densities for the entire campaign period, respectively. Enlarged views of daily observations and uncertainties of total column densities on 4 and 5 March 2006 are shown in panels (c) and (d), respectively. Red and blue dashed lines indicate the daily mean vertical column densities for the DA8 FTS and PARIS-IR, respectively. The errors for DA8 and PARIS-IR are the total percent errors given in Table 3. For the measurements using ozonesondes, the total columns were estimated by extrapolating above the highest measured altitude and the uncertainty given is $\pm 6 \%$ (taken from Tarasick et al., 2005).

from 27 February to 3 March 2006 because of clouds and snow at PEARL. There were good observing conditions at the end of the intensive phase, from 4 to 7 March 2006.

Figure 3 shows the time series of the individual (panel a) and the daily mean (panel b) ozone total column densities from the DA8 FTS and PARIS-IR obtained using the MWs near $1120 \mathrm{~cm}^{-1}$ (MW1120). Also included in these plots are the total columns estimated from the ozonesonde flights made during the campaign. These estimates were made by extrapolating the ozonesonde profile above the highest measured altitude and integrating to obtain a total column density as discussed in Tarasick et al. (2005). It can be seen that there are fewer DA8 FTS ozone measurements than PARISIR measurements in the early part of the campaign due to the sequence in which the filters are used for the observations. When the observing time during a day is less than $\sim 6-7 \mathrm{~h}$, the DA8 FTS cannot measure a full series of spectra (obtained by recording spectra with each filter twice) and thus not all of the target species have been measured every day by both ground-based FTSs. In contrast, PARIS-IR does not use narrow-band filters and, therefore, can provide column densities for all of the trace gases of interest from each observation. Results from PARIS-IR provide information with higher temporal resolution than those from the DA8 FTS. For example, on 4 March 2006, ten observations were made using PARIS-IR and the DA8 FTS simultaneously. Vertical column densities of ozone are available from all ten observations made using PARIS-IR on that day. However only two measurements were recorded by the DA8 FTS with the S6 filter $\left(700-1300 \mathrm{~cm}^{-1}\right)$ and thus only two ozone column results are available from MW1120. As indicated in Fig. 2, for the rest of that day, the DA8 FTS recorded atmospheric absorption spectra in spectral ranges other than the one covered by the S6 filter. Because of this, the spatial and temporal coverage of the PARIS-IR ozone measurements is much wider than that of the DA8 FTS. The impact of this difference in 
Table 3. Comparisons of total columns observed by the DA8 FTS and PARIS-IR from 21 February to 8 March 2006.

\begin{tabular}{lccc}
\hline \multirow{2}{*}{ Species } & MW $^{\mathrm{a}}$ & \multicolumn{2}{c}{ Mean Percentage Differences ${ }^{\mathrm{b}}$} \\
\cline { 3 - 4 } & & $\begin{array}{c}\text { Comparison Using Daily } \\
\text { Mean Value }(\%) \pm \text { Std. Dev. }\end{array}$ & $\begin{array}{c}\text { Comparison Using Individual } \\
\text { Measured Value }(\%) \pm \text { Std. Dev. }\end{array}$ \\
\hline $\mathrm{O}_{3}$ & 1120 & $-6.3 \pm 8.1$ & $2.8 \pm 5.7$ \\
& 2775 & $-3.6 \pm 3.9$ & $0.0 \pm 4.8$ \\
$\mathrm{HNO}_{3}$ & 868 & $-5.1 \pm 9.6$ & $-0.1 \pm 3.0$ \\
$\mathrm{ClONO}_{2}$ & 780 & $-2.2 \pm 7.3$ & $-1.9 \pm 2.6$ \\
$\mathrm{HF}$ & 4038 & $-17.6 \pm 10.1$ & $-4.3 \pm 6.7$ \\
$\mathrm{HCl}$ & 2725 & $-5.3 \pm 3.2$ & $-1.5 \pm 6.8$ \\
$\mathrm{NO}$ & 2914 & $-7.8 \pm 2.9$ & $-3.2 \pm 2.7$ \\
\hline
\end{tabular}

a See Table 1 for spectral ranges of microwindows.

${ }^{\mathrm{b}}$ See text for calculation method description. Uncertainty given is the $1 \sigma$ standard deviation of the mean difference.

sampling is seen in panel c of Fig. 3. Here, the individual PARIS-IR and DA8 FTS MW1120 ozone observations from 4 March 2006 are shown and the daily mean value is indicated. When the measurements from the two FTSs were made simultaneously, there was good agreement within the respective uncertainties. However, because the ozone column densities retrieved by PARIS-IR differed throughout the day as the measurement location and time changed, the daily mean values for the DA8 FTS and PARIS-IR do not agree as well as the simultaneous measurements. These differences observed between the daily mean comparisons and individual comparisons vary with day and with species. Panel $d$ of Fig. 3 shows the ozone total column density results for PARIS-IR and the DA8 FTS on 5 March 2006. Here the daily mean results are in better agreement. Figures 4 and 5 provide similar comparisons for $\mathrm{HCl}, \mathrm{ClONO}_{2}, \mathrm{HNO}_{3}, \mathrm{HF}$, and $\mathrm{NO}_{2}$ total column densities on 5 March and 7 March 2006, respectively. The daily mean and individual comparisons for these days generally agree within the uncertainties.

To investigate this further, we calculated the differences between the PARIS-IR and DA8 FTS total column densities for the six species $\left(\mathrm{O}_{3}, \mathrm{HNO}_{3}, \mathrm{HCl}, \mathrm{NO}_{2}, \mathrm{ClONO}_{2}\right.$, and $\mathrm{HF}$ ) and these are shown in Table 3 (note that PARIS-IR did not measure NO). The comparisons were performed in two ways, one approach using daily mean values and the other approach using individual measurements. For the former method, daily mean total column densities were calculated for a given species retrieved by both FTSs, and percentage differences were calculated for each measurement day using

$P_{x}=\frac{\left[\bar{C}_{P x}-\bar{C}_{D x}\right]}{\bar{C}_{P x}} \times 100$,

where, $\bar{C}_{P x}$ and $\bar{C}_{D x}$ are the daily mean values of observed total columns of the given species $x$ ( $x$ can be $\mathrm{O}_{3}, \mathrm{HNO}_{3}$,
$\mathrm{HCl}, \mathrm{NO}_{2}, \mathrm{ClONO}_{2}$, or HF) observed by PARIS-IR and the DA8 FTS, respectively. All of the percentage differences were then averaged to obtain the results shown in the third column of Table 3 together with the $1 \sigma$ standard deviation of the differences. In the second comparison method, differences between individual measurements were calculated using

$P_{x}=\frac{\left[C_{P x}-C_{D x}\right]}{C_{P x}} \times 100$,

where, $C_{P x}$ and $C_{D x}$ are the individual values of simultaneously observed total columns. All of these differences between individual measurements were then averaged to obtain the results shown in the fourth column of Table 3 (along with the $1 \sigma$ standard deviation of the mean).

For all six of the species investigated, the comparisons using daily mean values show larger differences (by up to $13 \%$ ) between two FTSs than those using the individual observations recorded simultaneously. Variation in the measured total column densities during each observation day, as shown in Figs. 3, 4, and 5, arises primarily from the temporal and spatial differences in Arctic atmospheric composition. This variation has to be taken into consideration when making comparisons between ground-based instruments measuring at high latitudes and when choosing coincidence criteria for satellite comparison studies.

The differences between the simultaneous measurements made by the DA8 FTS and PARIS-IR can be compared to results from earlier intercomparison campaigns. In 1999, an instrument comparison campaign was held at Eureka and the retrieved vertical columns from the portable NPL FTS (a Bruker 120M) were compared with those from the DA8 FTS at PEARL (Murphy et al., 2001; Paton-Walsh et al., 2008). These comparisons show that the differences between 

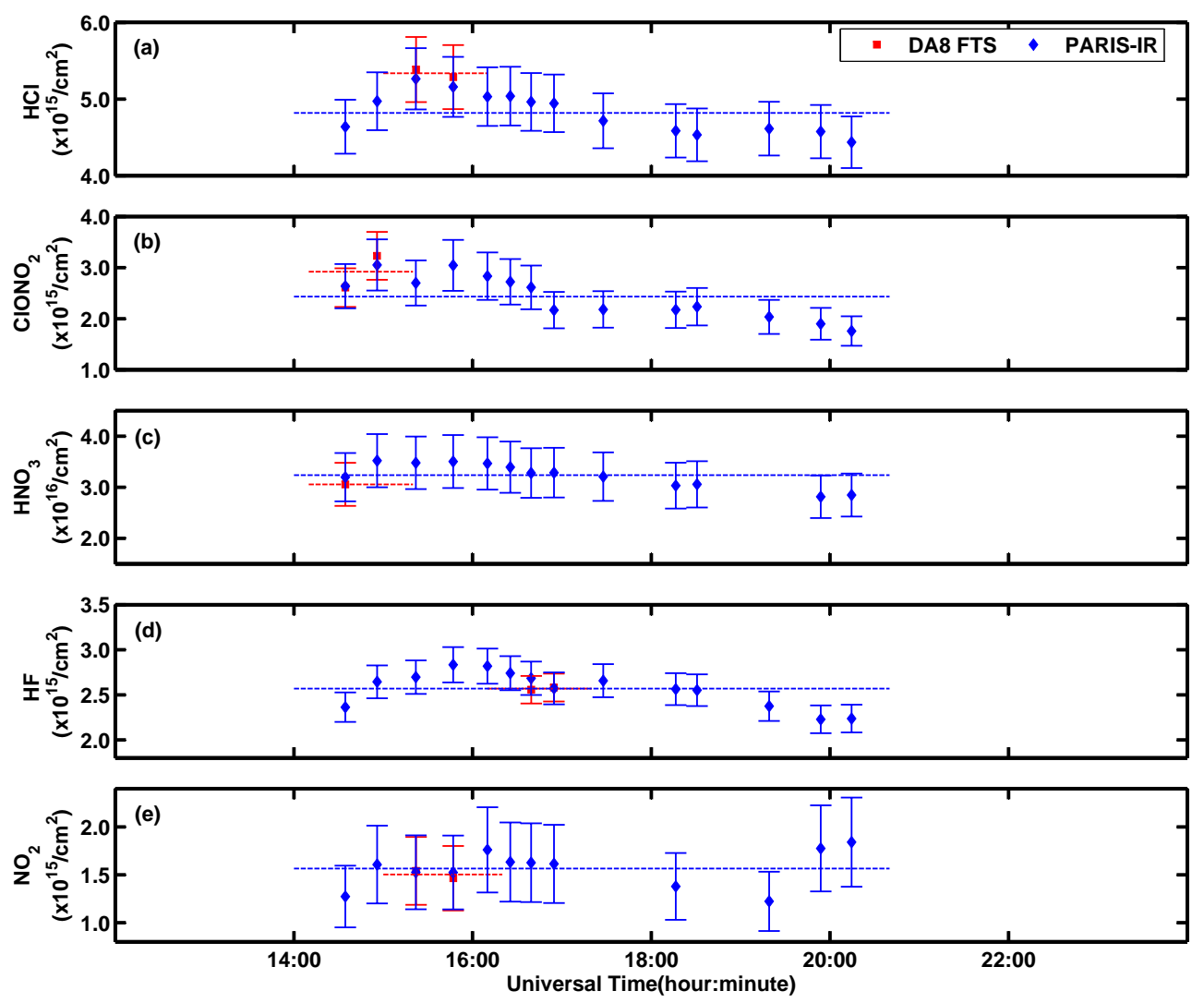

Fig. 4. Total vertical column densities of $\mathrm{HCl}$ (a), $\mathrm{ClONO}_{2}$ (b), $\mathrm{HNO}_{3}\left(\mathrm{MW} \mathrm{868)}\right.$ (c), $\mathrm{HF}$ (d), and $\mathrm{NO}_{2}$ (e) retrieved from spectra obtained with PARIS-IR and the DA8 FTS at PEARL on 5 March 2006. Error bars indicate the DA8 FTS and PARIS-IR total percentage errors given in Table 2. Red dashed lines and blue dashed lines indicate the daily mean total column densities measured by the DA8 FTS (red squares) and PARIS-IR (blue diamonds), respectively.

the NPL FTS and the DA8 FTS have a consistent systematic bias of about $3 \%$ for $\mathrm{HCl}, \mathrm{HNO}_{3}$ and $\mathrm{O}_{3}$, and $7 \%$ for $\mathrm{HF}$, with the DA8 FTS reporting higher column amounts than the NPL FTS for all comparisons. The large difference between instruments for HF was attributed to an instrument lineshape problem and a zero level problem (when the atmosphere has $100 \%$ absorption the signal should be zero). In addition, the non-linearity of the MCT detector was found to be causing a major portion of the differences in retrieved $\mathrm{HNO}_{3}$ columns between the NPL FTS and the DA8 FTS. The mean individual differences obtained from the 2006 Canadian Arctic ACE Validation Campaign are generally similar to or smaller than those reported in the 1999 comparison and these differences show systematically lower column values for five species $\left(\mathrm{HNO}_{3}, \mathrm{HCl}, \mathrm{NO}_{2}, \mathrm{ClONO}_{2}\right.$, and $\left.\mathrm{HF}\right)$ and higher column values for $\mathrm{O}_{3}$ from PARIS-IR than from the DA8 FTS. For all species except $\mathrm{O}_{3}$, the results from the current work are consistent with the earlier NPL intercomparison study.

The different spectral resolutions of the instruments could also contribute to the differences between the PARIS-IR and DA8 FTS. This was investigated during comparisons between PARIS-IR and two FTSs with higher spectral resolu- tions that were carried out in summer 2005 at the University of Toronto (Wunch et al., 2007). One of these FTSs was the Toronto Atmospheric Observatory Fourier Transform Spectrometer (TAO-FTS), an ABB Bomem DA8 FTS with the same specifications as the Eureka DA8 FTS. Total column differences for $\mathrm{O}_{3}$ and $\mathrm{HCl}$ between PARIS-IR and the TAOFTS were found to be about $\pm 1 \%$ to $+4 \%$, respectively, consistent in magnitude with the agreement between PARIS-IR and the Eureka DA8 FTS in this work. However, it should be noted that the $\mathrm{MW}$ regions for $\mathrm{HCl}$ and $\mathrm{O}_{3}$ used in the two studies were different and this may contribute to the difference.

\subsection{Partial column comparisons between ACE-FTS measurements and ground-based FTS observations}

The concentration profiles of trace gases retrieved from ground-based observations provide limited vertical resolution (DOFS about 1 to 4 over the altitude range from the ground to $100 \mathrm{~km}$, as shown in Table 2), much coarser than the vertical resolution (about 3-4 km) of observations from ACE-FTS. Because of this, the present comparisons are 

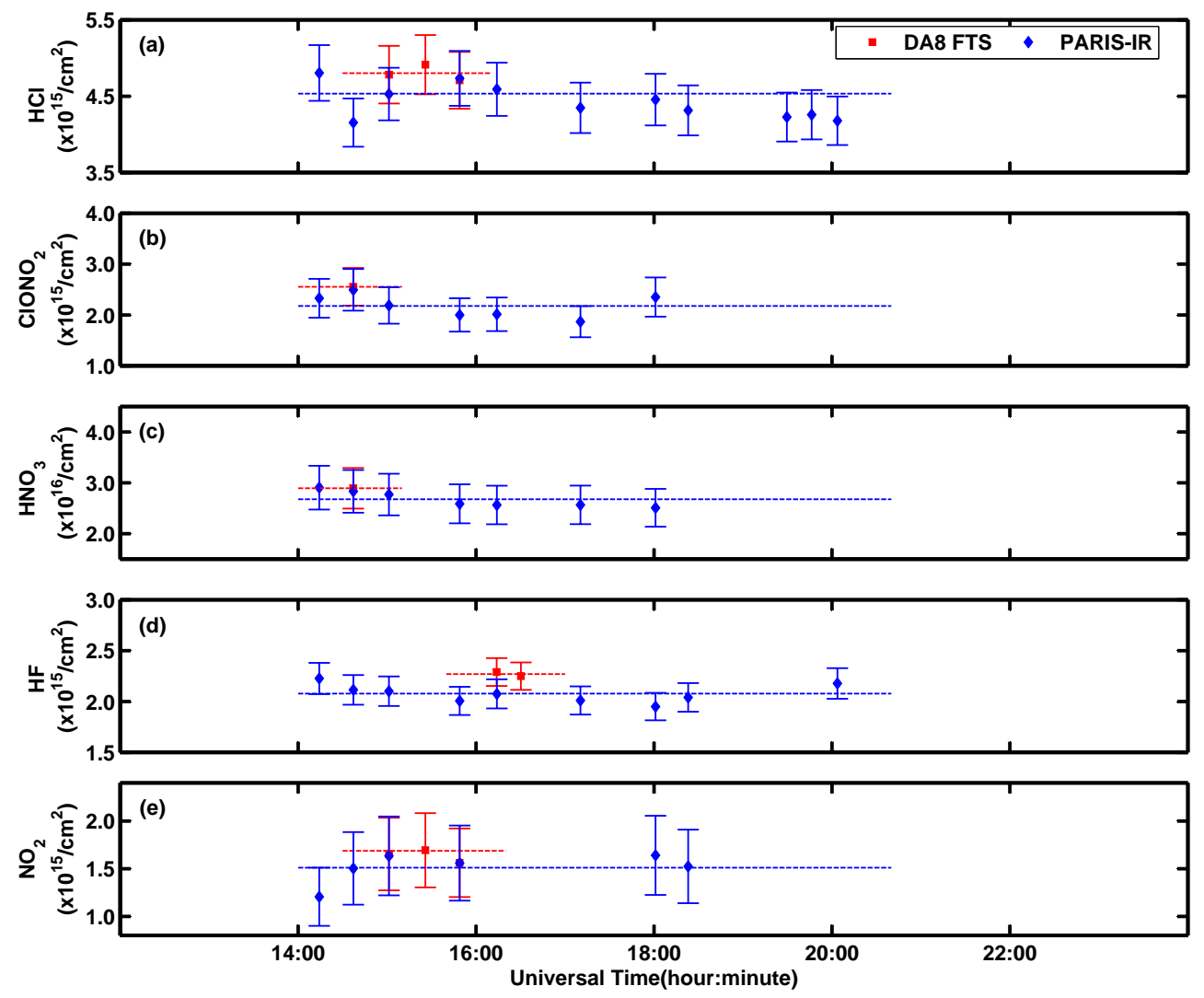

Fig. 5. Same as Fig. 4 but for 7 March 2006.

restricted to partial column abundances rather than profiles. As shown in Sung et al. (2007), the comparisons of partial columns from ground-based instruments with ACE-FTS results poses difficulties for molecules with maximum VMR in the troposphere (such as $\mathrm{N}_{2} \mathrm{O}$ or $\mathrm{CH}_{4}$ ), particularly for an FTS with the resolution of PARIS-IR. Thus, we restrict our comparisons to molecules where the VMR peaks in the stratosphere.

There were 13 occultation measurements within $500 \mathrm{~km}$ of PEARL during the campaign. Coincident ground-based measurements occurred on eight days for the DA8 FTS and seven days for PARIS-IR, with multiple coincidences on some days for each instrument. The partial columns, $C_{x}$, of the seven trace gases were calculated for ACE-FTS using

$C_{x}=\sum_{i=\text { bottom }}^{i=\text { top }} \rho(i) \times \mathrm{VMR}_{x}(i) \times Z(i)$,

where $x$ stands for $\mathrm{O}_{3}, \mathrm{HCl}, \mathrm{ClONO}_{2}, \mathrm{HF}, \mathrm{HNO}_{3}, \mathrm{NO}_{2}$, or NO. $\rho(i)$ (in molecules $/ \mathrm{cm}^{3}$ ), $\mathrm{VMR}_{x}(i)$, and $Z(i)$ (in $\mathrm{cm}$ ) are the number density of air, the volume mixing ratio of the species $x$ in the $i$ th layer, and the thickness of the $i$ th layer. The occultation measurements made by the ACE-FTS usually have different altitude ranges due to factors such as clouds limiting how low in altitude the measurements extend. Therefore, common altitude ranges were used for the partial columns calculated from the ACE-FTS profiles. These results are shown in Table 4 together with their altitude ranges, measurement dates, and occultation names. In addition, the uncertainty in each partial column density, as determined from the root-sum-square of the spectral fitting error from the corresponding ACE-FTS profile, is given.

For the two species where retrievals for the DA8 FTS and PARIS-IR were performed using two different MWs, only one was chosen for the comparisons with ACE-FTS based on the reasoning given below. The ACE-FTS version 2.2 ozone update retrievals use a wide spectral region near $1120 \mathrm{~cm}^{-1}$ containing a high density of $\mathrm{O}_{3}$ absorption lines. During the development of the version $2.2 \mathrm{O}_{3}$ update, it was found that retrievals made using lines near $1100 \mathrm{~cm}^{-1}$ and those near $2775 \mathrm{~cm}^{-1}$ differed by $\sim 5 \%$ due to the spectroscopic parameters. To avoid this known inconsistency, $\mathrm{O}_{3}$ column densities from MW2775 were not included in this section. For $\mathrm{HNO}_{3}$, both MW868 and MW872 results were available from the PARIS-IR and the DA8 FTS and, as shown in the previous section, are in good agreement (within $2 \%$ ) in the total column density. The results from MW868 were used in the comparison with ACE-FTS since there was slightly better agreement between two ground-based FTSs for this MW than for MW872.

Since $\mathrm{NO}_{2}$ and $\mathrm{NO}$ experience significant diurnal variations, differences between the local times of the ACE-FTS 
Table 4. Partial columns calculated from ACE-FTS measurements taken during the 2006 Canadian Arctic ACE Validation Campaign.

\begin{tabular}{|c|c|c|c|c|c|c|c|c|c|c|}
\hline \multirow[t]{2}{*}{$\begin{array}{c}\text { Date } \\
\mathrm{mm} / \mathrm{dd}\end{array}$} & \multirow{2}{*}{$\begin{array}{l}\text { Time (UT) } \\
\text { hh:mm:ss }\end{array}$} & \multirow[t]{2}{*}{$\begin{array}{l}\text { Occult. } \\
\text { Name }\end{array}$} & \multirow{2}{*}{$\begin{array}{c}\text { Distance } \Delta^{\mathrm{c}} \\
(\mathrm{km})\end{array}$} & $\begin{array}{c}\mathrm{O}_{3} \\
\left(\times 10^{19}\right)\end{array}$ & $\begin{array}{c}\mathrm{HCl} \\
\left(\times 10^{15}\right)\end{array}$ & $\begin{array}{l}\mathrm{ClONO}_{2} \\
\left(\times 10^{15}\right)\end{array}$ & $\begin{array}{c}\mathrm{HF} \\
\left(\times 10^{15}\right)\end{array}$ & $\begin{array}{c}\mathrm{HNO}_{3} \\
\left(\times 10^{16}\right)\end{array}$ & $\begin{array}{c}\mathrm{NO}_{2} \\
\left(\times 10^{15}\right)\end{array}$ & $\begin{array}{c}\text { NO } \\
\left(\times 10^{15}\right)\end{array}$ \\
\hline & & & & \multicolumn{7}{|c|}{$\left(\text { molecules } / \mathrm{cm}^{2}\right)^{\mathrm{d}}$} \\
\hline $2 / 22$ & $21: 32: 40$ & ss13631 & 449 & $1.16(2)$ & $4.4(3)$ & $1.6(3)$ & $1.92(11)$ & $2.69(4)$ & $0.82(3)$ & $2.3(1)$ \\
\hline $2 / 23$ & $20: 20: 45$ & ss 13645 & 201 & $1.11(2)$ & $4.4(3)$ & $1.6(2)$ & $1.92(12)$ & $2.62(5)$ & $1.25(4)$ & $2.9(2)$ \\
\hline $2 / 26$ & $20: 00: 13$ & ss13689 & 92 & $1.11(2)$ & $4.4(3)$ & $1.8(2)$ & $2.06(10)$ & $2.58(4)$ & $0.96(3)$ & $2.2(1)$ \\
\hline $2 / 28$ & $20: 51: 34$ & ss 13719 & 119 & $1.10(2)$ & $4.3(2)$ & $2.0(2)$ & $2.08(09)$ & $2.59(2)$ & $0.78(3)$ & $2.2(2)$ \\
\hline $3 / 1$ & $21: 17: 13$ & ss13734 & 202 & $1.16(2)$ & $4.4(2)$ & $2.4(2)$ & $2.30(09)$ & $2.78(4)$ & $1.21(3)$ & $2.3(1)$ \\
\hline $3 / 4$ & $20: 56: 26$ & ss13778 & 95 & $0.94(1)$ & $4.0(2)$ & $1.4(1)$ & $1.73(07)$ & $2.17(3)$ & $1.17(3)$ & $2.4(1)$ \\
\hline $3 / 5$ & 21:22:04 & ss13793 & 64 & $1.11(4)$ & $4.6(2)$ & $2.4(2)$ & $2.43(09)$ & $2.99(5)$ & $1.04(2)$ & $2.4(1)$ \\
\hline $3 / 5$ & $22: 59: 47$ & ss13794 & 445 & $1.03(3)$ & $4.3(2)$ & $1.7(1)$ & $2.16(08)$ & $2.60(4)$ & $1.06(2)$ & $2.6(1)$ \\
\hline $3 / 6$ & $21: 47: 43$ & ss13808 & 63 & $1.05(2)$ & $4.4(2)$ & $2.2(2)$ & $2.26(08)$ & 2.61(3) & $1.01(2)$ & $2.5(1)$ \\
\hline $3 / 6$ & $23: 25: 25$ & ss13809 & 497 & $1.02(2)$ & $4.2(2)$ & $1.6(1)$ & $2.02(08)$ & $2.44(3)$ & $1.05(3)$ & $2.3(1)$ \\
\hline $3 / 7$ & $22: 13: 21$ & ss13823 & 98 & $1.03(2)$ & $4.3(2)$ & $1.9(1)$ & $2.22(07)$ & $2.36(3)$ & $1.19(5)$ & $2.5(1)$ \\
\hline $3 / 8$ & $22: 38: 59$ & ss 13838 & 152 & $1.14(2)$ & $4.5(2)$ & $1.8(1)$ & $2.22(07)$ & $2.74(3)$ & $1.14(2)$ & $2.6(1)$ \\
\hline $3 / 13$ & $23: 09: 33$ & ss13912 & 357 & $1.20(1)$ & $4.9(1)$ & $3.0(2)$ & $2.84(09)$ & $3.51(2)$ & $1.32(4)$ & $2.3(2)$ \\
\hline \multicolumn{4}{|c|}{ Partial Column Altitude Range (km) } & $9.5-84.5$ & $11.5-47.5$ & $14.5-30.5$ & $13.5-44.5$ & $10.5-31.5$ & $17.5-35.5$ & $24.5-84.5$ \\
\hline
\end{tabular}

${ }^{a}$ Universal time of ACE-FTS observations.

$\mathrm{b}$ Occultation names used by the ACE Science Operations Centre to label occultations [type of measurement $(\mathrm{sr}=$ sunrise and ss $=$ sunset $)+$ orbit number].

${ }^{c} \Delta$ is distance from ACE-FTS occultation measurement to PEARL.

d ACE-FTS partial column error was calculated from the spectral fitting error for each measurement. This value is given in parentheses.

and ground-based observations can contribute to discrepancies in the comparisons. To account for this, we have adopted the "diurnal mapping" technique used by Kerzenmacher et al. (2008) in the ACE $\mathrm{NO}_{2}$ and $\mathrm{NO}$ validation study (Sect. 4.1). Briefly, this technique uses the output from a chemical box model (McLinden et al., 2006) to scale the result from one instrument at one local time to the local time of other instrument. The diurnal scaling factors have been calculated for each ACE-FTS occultation and have been used to map the ACE-FTS profiles to the local times of the groundbased FTS measurements, prior to calculating the partial column densities.

As mentioned at the beginning of this section, the location of the polar vortex needs to be taken into account for comparisons of measurements made at high latitudes. The ACE-FTS partial column densities described above can be used to demonstrate the importance of this additional coincidence consideration. For example, three sunset measurements named ss13778, ss13793 and ss13794 were made within $500 \mathrm{~km}$ of PEARL by the ACE-FTS on 4 and 5 March 2006 (Fig. 2). The observation times for ss13778, ss13793 and ss13794 were 20:56:26 UT (4 March), 21:22:04 UT (5 March) and 22:59:47 UT (5 March), respectively. The partial columns for ss13793 and ss13794 (given in Table 4) show percentage differences of $-8.11 \%$, $-6.79 \%,-38.06 \%,-12.32 \%,-14.88 \%, 1.96 \%$, and $7.67 \%$ for $\mathrm{O}_{3}, \mathrm{HCl}, \mathrm{ClONO}_{2}, \mathrm{HF}, \mathrm{HNO}_{3}, \mathrm{NO}_{2}$, and $\mathrm{NO}$, respectively. For $\mathrm{O}_{3}, \mathrm{HCl}, \mathrm{NO}_{2}$ and $\mathrm{NO}$, these percentage differences are approximately within the combined estimated uncertainty of the partial column densities. However, for the other three species, the differences are larger than the uncertainty estimates. For ss 13778 and ss13793, which differ in space by $\sim 30 \mathrm{~km}$ and time by $\sim 24 \mathrm{~h}$, the observed partial columns show percentage differences of $-18.14 \%$, $-16.83 \%,-71.18 \%,-40.51 \%,-37.45 \%, 11.14 \%$, and $-3.21 \%$, for $\mathrm{O}_{3}, \mathrm{HCl}, \mathrm{ClONO}_{2}, \mathrm{HF}, \mathrm{HNO}_{3}, \mathrm{NO}_{2}$, and $\mathrm{NO}$, respectively. These differences are much larger than the combined uncertainty estimates for all species except for NO. To determine if the same air mass was being sampled by these pairs of ACE-FTS measurements, the location of the polar vortex was investigated using SPV (in units of $10^{-4} \mathrm{~s}^{-1}$ ) calculated from the Goddard Earth Observing System version 4.03 (GEOS-4) analyses (Bloom et al., 2005). These results were obtained from the Derived Meteorological Products (DMPs) provided for the ACE-FTS occultation measurements (Manney et al., 2007). For these three occultations, the SPV values at two altitudes (potential temperature levels) along the measurement were compared: $18.5 \mathrm{~km}$ $(\sim 465 \mathrm{~K})$ and $30.5 \mathrm{~km}(\sim 760 \mathrm{~K})$ were chosen because they are near the peak in number density for $\mathrm{O}_{3}, \mathrm{HCl}, \mathrm{ClONO}_{2}$, $\mathrm{HF}$, and $\mathrm{HNO}_{3}$, and $\mathrm{NO}_{2}$ and $\mathrm{NO}$, respectively. At 18.5 $\mathrm{km}$, the sPV values for ss13778, ss13794 and ss13793 are $1.07 \times 10^{-4} \mathrm{~s}^{-1}, 1.24 \times 10^{-4} \mathrm{~s}^{-1}$ and $1.37 \times 10^{-4} \mathrm{~s}^{-1}$, respectively, corresponding to the measurement location moving from outside of the polar vortex into the vortex edge region. For the $30.5 \mathrm{~km}$ level, the values are $1.94 \times 10^{-4} \mathrm{~s}^{-1}$, $2.22 \times 10^{-4} \mathrm{~s}^{-1}$, and $2.26 \times 10^{-4} \mathrm{~s}^{-1}$ for ss13778, ss 13794 and ss 13793 , respectively, which are all within the vortex. The change in the column densities of $\mathrm{O}_{3}, \mathrm{HCl}, \mathrm{ClONO}_{2}$, $\mathrm{HF}$ and $\mathrm{HNO}_{3}$ for ss 13778 , ss 13794 and ss 13793 is mirrored 
in the change in sPV at $18.5 \mathrm{~km}$. Similarly, at $30.5 \mathrm{~km}$, the change in SPV has the same behaviour as the change in $\mathrm{NO}_{2}$ column density. Because of the magnitude of the uncertainty, no comment can be made about the trend in NO column density. This shows that considering sPV, in addition to spatial and temporal coincidence criteria, can assist in determining if similar air masses are being compared. It should be noted that the polar vortex in the lower stratosphere was rather poorly defined during the campaign (see Manney et al., 2008 and discussion at beginning of Sect. 5). Because the lower stratospheric vortex was weak with a lot of mixing with extravortex air, there is likely to be more day-to-day and measurement-to-measurement variability seen in these results than can be accounted for using a "strict" sPV vortex edge criterion.

To compare the partial column densities calculated from the ACE-FTS measurements with those from PARIS-IR and the DA8 FTS, the difference in the vertical resolution between the measurements has to be taken into account. This was done by smoothing the VMR profiles from the ACEFTS using the averaging kernels from PARIS-IR and DA8 FTS retrievals (Rodgers and Connor, 2003). The VMR profiles from ACE-FTS were interpolated on to the 29-layer grid used for the ground-based FTSs. These profiles were extended below the lowest retrieved altitude using information from the ground-based FTS a priori profiles. Then these composite profiles were smoothed using the DA8 FTS and PARIS-IR averaging kernels and a priori profile. The vertical partial columns were recalculated using the smoothed ACEFTS profiles in place of $\mathrm{VMR}_{x}(i)$ in Eq. (3). These smoothed ACE-FTS partial column densities were divided by the partial column results from the DA8 FTS and PARIS-IR (calculated over the same altitude range) to obtain the ratios in Table 5. Also, the mean percentage differences ( $\{[$ ACE-FTS $]-$ [ground-based FTS]\}/[ground-based FTS]) and the $1 \sigma$ standard deviation of the differences were calculated. As mentioned earlier, in order to make valid comparisons, the altitude ranges for the PARIS-IR and DA8 FTS partial columns were chosen to match those used for ACE-FTS. Over these altitude ranges, the PARIS-IR and DA8 FTS retrievals have averaging kernel values generally larger than 0.5 (as shown in Fig. 1), which indicates that retrieved columns of the investigated species are primarily obtained from observations rather than a priori information. All ACE-FTS measurements within $500 \mathrm{~km}$ of PEARL were used for this comparison. For PARIS-IR, the partial column densities of individual groundbased observations that were closest in time to the ACE-FTS observation were used. For the DA8 FTS, the daily mean of the partial column densities was used. Typically, two measurements were taken sequentially with each filter on each day with up to four sequential measurements on some days.

In Table 5, with the exception of the $\mathrm{HNO}_{3}$ comparisons for PARIS-IR, the mean differences in the partial column densities between the ground-based FTSs and ACE-FTS are negative. However, for all of the species, the mean ratios and mean percentage differences are smaller than the total errors for the DA8 FTS and PARIS-IR reported in Table 2. The largest variation in the ratios is for $\mathrm{ClONO}_{2}$ for which the standard deviations of the mean difference are $28.3 \%$ and $14.2 \%$ for DA8 FTS and PARIS-IR, respectively. To some degree, this reflects the challenge in retrieving this molecule from the ground-based spectra.

In general, for the investigated atmospheric species, PARIS-IR shows better agreement with ACE-FTS than does the DA8 FTS. This is most likely due to better temporal coincidences. The temporal and spatial differences between the ACE-FTS and ground-based instruments are shown in Table 6 for PARIS-IR and Tables 7-10 for the DA8 FTS (each table corresponds to the group of molecules measured in each filter region). The PARIS-IR measurements are taken up to $\sim 4 \mathrm{~h}$ before the ACE-FTS occultation, with an average difference of $\sim 2 \mathrm{~h}$. For the DA8-FTS, the maximum temporal differences are between $\sim 5$ and $\sim 8.5 \mathrm{~h}$ and the average differences are $\sim 3.5$ to $\sim 7 \mathrm{~h}$. All of the ACE-FTS measurements were selected because they occurred within $500 \mathrm{~km}$ of PEARL. However, this does not necessarily reflect the distance between the ACE-FTS occultation and the ground-based FTS measurement. This was calculated using the method described above and the distances between the ACE-FTS occultation location and the ground-based measurement location (using $18-\mathrm{km}$ altitude as representative of the region of the atmosphere being sampled) are given in Tables 6-10. The spatial differences between the ACEFTS and PARIS-IR observations are on average $400 \mathrm{~km}$ with a maximum of $700 \mathrm{~km}$. For the DA8 FTS and ACE-FTS comparisons, the maximum spatial differences are $\sim 500$ $600 \mathrm{~km}$ and the average values are between 300 and $400 \mathrm{~km}$. Because these distances between the measurements can be larger than the stated distance coincidence criterion, it is important to ensure that the comparisons are considering similar air masses using sPV. This is given in Tables 6 through 10 for the $\sim 18 \mathrm{~km}$ and $\sim 30 \mathrm{~km}$ altitudes for each of the measurements. Based on the values at $\sim 18 \mathrm{~km}$, these measurements are primarily sampling outside or on the edge of the vortex $\left(\mathrm{sPV}<1.4 \times 10^{-4} \mathrm{~s}^{-1}\right)$ with the exception of 13 March 2006 where both are inside ( $\mathrm{sPV} \sim 1.8 \times 10^{-4} \mathrm{~s}^{-1}$ ). This is consistent with the weak and poorly defined vortex in the lower stratosphere after the SSW. At $\sim 30 \mathrm{~km}$, all sPV values are greater than $1.6 \times 10^{-4} \mathrm{~s}^{-1}$ indicating that the measurements are sampling inside the vortex. These values tend to increase throughout the period and are consistent with the vortex increasing in strength and reforming over Eureka. At both levels, there are no obvious mismatches (one measurement inside and the other outside) which could contribute to the differences seen between the ACE-FTS and ground-based measurements.

As part of the validation of the ACE-FTS version 2.2 (plus updates) data products, comparisons of partial column densities have been made between measurements by ACEFTS and high-resolution ground-based FTSs. The same 
Table 5. Ratios of partial columns ([ACE-FTS]/[ground-based FTS]) obtained during the 2006 Canadian Arctic ACE Validation Campaign.

\begin{tabular}{|c|c|c|c|c|c|c|c|c|c|c|c|c|c|c|c|c|}
\hline \multirow{2}{*}{$\begin{array}{c}\text { Date } \\
\mathrm{mm} / \mathrm{dd}\end{array}$} & \multirow{2}{*}{$\begin{array}{l}\text { Time (UT) } \\
\text { hh:mm:ss }\end{array}$} & \multirow{2}{*}{$\begin{array}{c}\text { Occultation } \\
\Delta^{\mathrm{b}}(\mathrm{km})\end{array}$} & \multicolumn{2}{|c|}{$\mathrm{O}_{3}$} & \multicolumn{2}{|c|}{$\mathrm{HCl}$} & \multicolumn{2}{|c|}{$\mathrm{ClONO}_{2}$} & \multicolumn{2}{|c|}{$\mathrm{HF}$} & \multicolumn{2}{|c|}{$\mathrm{HNO}_{3}$} & \multicolumn{2}{|c|}{$\mathrm{NO}_{2}$} & \multicolumn{2}{|c|}{ NO } \\
\hline & & & $\mathrm{AD}^{\mathrm{c}}$ & $\mathrm{AP}^{\mathrm{d}}$ & $\mathrm{AD}$ & $\mathrm{AP}$ & $\mathrm{AD}$ & $\mathrm{AP}$ & $\mathrm{AD}$ & AP & $\mathrm{AD}$ & $\mathrm{AP}$ & $\mathrm{AD}$ & AP & $\mathrm{AD}$ & AP \\
\hline $2 / 22$ & $21: 32: 40$ & ss13631 (449) & - & - & - & - & - & - & - & - & - & - & - & - & - & - \\
\hline $2 / 23$ & $20: 20: 45$ & ss13645 (201) & - & 0.87 & 0.98 & 0.94 & - & 1.12 & 0.91 & 0.91 & - & 1.02 & 0.92 & 1.09 & - & - \\
\hline $2 / 26$ & $20: 00: 13$ & ss13689 (092) & - & 0.97 & 0.89 & 0.96 & - & 0.92 & 1.03 & 0.94 & - & 0.96 & 0.88 & 0.97 & - & - \\
\hline $2 / 28$ & $20: 51: 34$ & ss13719(119) & - & - & - & - & - & - & - & - & - & - & - & - & - & - \\
\hline $3 / 1$ & $21: 17: 13$ & ss13734 (202) & - & - & - & - & - & - & - & - & - & - & - & - & - & - \\
\hline $3 / 4$ & $20: 56: 26$ & ss $13778(095)$ & 0.87 & 0.90 & 0.81 & 0.90 & 0.53 & 0.89 & - & 0.83 & 0.71 & 0.95 & 0.68 & 1.00 & 1.07 & - \\
\hline $3 / 5$ & $21: 22: 04$ & ss 13793 (064) & 0.89 & 0.98 & 0.95 & 0.97 & 0.96 & 0.99 & 1.01 & 1.00 & 1.09 & 1.23 & 0.75 & 1.02 & 0.93 & - \\
\hline $3 / 5$ & $22: 59: 47$ & ss $13794(445)$ & 0.91 & 0.89 & 0.83 & 0.95 & 0.61 & 1.00 & 0.94 & 1.00 & 0.93 & 1.04 & 0.76 & 0.83 & 0.94 & - \\
\hline $3 / 6$ & $21: 47: 43$ & ss13808 (063) & 0.95 & 0.99 & 0.95 & 0.97 & 1.20 & 1.24 & 1.06 & 1.00 & 1.04 & 1.16 & 0.72 & 0.80 & 0.90 & - \\
\hline $3 / 6$ & $23: 25: 25$ & ss13809 (497) & 0.92 & 0.95 & 0.91 & 0.93 & 0.76 & 0.81 & 0.98 & 0.97 & 0.97 & 1.08 & 0.70 & 0.78 & 0.89 & - \\
\hline $3 / 7$ & $22: 13: 21$ & ss13823 (098) & 0.88 & 1.04 & 0.97 & 1.01 & 0.83 & 0.86 & 1.06 & 0.98 & 0.87 & 1.02 & 0.66 & 0.55 & 0.99 & - \\
\hline $3 / 8$ & $22: 38: 59$ & ss13838 (152) & - & - & - & - & - & - & - & - & - & - & - & - & - & - \\
\hline $3 / 13$ & $23: 09: 33$ & ss13912 (357) & 1.16 & - & 0.94 & - & 1.28 & - & 0.94 & - & - & - & 0.99 & - & 0.74 & - \\
\hline \multicolumn{3}{|c|}{ Mean Column Ratio } & 0.94 & 0.95 & 0.92 & 0.95 & 0.88 & 0.98 & 0.99 & 0.95 & 0.93 & 1.06 & 0.78 & 0.88 & 0.92 & - \\
\hline \multicolumn{3}{|c|}{ Mean Percentage Difference ${ }^{\mathrm{e}}(\%)$} & -5.9 & -5.2 & -8.5 & -4.6 & -11.8 & -2.3 & -0.9 & -4.7 & -6.6 & 5.7 & -21.6 & -11.9 & -7.6 & - \\
\hline \multicolumn{3}{|c|}{$1 \sigma$ Standard Deviation $(\%)$} & 10.0 & 5.8 & 5.8 & 3.3 & 28.3 & 14.2 & 5.8 & 6.1 & 13.6 & 9.6 & 11.5 & 17.3 & 10.2 & - \\
\hline \multicolumn{3}{|c|}{ Partial Column Altitude Range (km) } & \multicolumn{2}{|c|}{$9.5-84.5$} & \multicolumn{2}{|c|}{$11.5-47.5$} & \multicolumn{2}{|c|}{$14.5-30.5$} & \multicolumn{2}{|c|}{$13.5-44.5$} & \multicolumn{2}{|c|}{$10.5-31.5$} & \multicolumn{2}{|c|}{$17.5-35.5$} & \multicolumn{2}{|c|}{$24.5-84.5$} \\
\hline
\end{tabular}

a Universal time of ACE-FTS observations.

$\mathrm{b}^{\mathrm{b}} \mathrm{\text {is }}$ distance from ACE-FTS occultation measurement to PEARL.

c Ratio of [ACE-FTS]/[DA8].

d Ratio of [ACE-FTS]/[PARIS-IR].

e ([ACE-FTS]-[Ground-Based FTS])/[Ground-Based FTS].

Table 6. The spatial and temporal differences between PARIS-IR and ACE-FTS observations of $\mathrm{O}_{3}, \mathrm{HCl} \mathrm{ClONO}_{2}, \mathrm{HF} \mathrm{HNO}_{3}$, and $\mathrm{NO}_{2}$ during the 2006 Canadian Arctic ACE Validation Campaign.

\begin{tabular}{|c|c|c|c|c|c|c|c|c|c|c|}
\hline \multirow{2}{*}{$\begin{array}{c}\text { Date } \\
\mathrm{mm} / \mathrm{dd}\end{array}$} & \multirow{2}{*}{$\begin{array}{l}\text { ACE Time }^{\mathrm{a}} \\
\text { hh:mm:ss }\end{array}$} & \multirow[t]{2}{*}{ Occultation } & \multirow{2}{*}{$\begin{array}{c}\Delta_{1}^{\mathrm{b}} \\
(\mathrm{km})\end{array}$} & \multirow{2}{*}{$\begin{array}{c}\Delta_{2}^{\mathrm{c}} \\
(\mathrm{km})\end{array}$} & \multirow{2}{*}{$\begin{array}{c}\text { PARIS-IR Time } \\
\text { hh:mm:ss }\end{array}$} & \multirow{2}{*}{$\begin{array}{c}\Delta_{3}^{\mathrm{d}} \\
\text { (hours) }\end{array}$} & \multicolumn{2}{|c|}{$\mathrm{sPV} 18 \mathrm{~km}\left(10^{-4} \mathrm{~s}^{-1}\right)^{\mathrm{e}}$} & \multicolumn{2}{|c|}{$\mathrm{sPV} 30 \mathrm{~km}\left(10^{-4} \mathrm{~s}^{-1}\right)^{\mathrm{f}}$} \\
\hline & & & & & & & ACE-FTS & PARIS-IR & ACE-FTS & PARIS-IR \\
\hline $2 / 22$ & $21: 32: 40$ & ss 13631 & 449 & - & - & - & 1.17 & - & 1.71 & - \\
\hline $2 / 23$ & $20: 20: 45$ & ss 13645 & 201 & 408 & $18: 53: 32$ & 1.45 & 0.97 & 0.94 & 1.68 & 2.21 \\
\hline $2 / 26$ & 20:00:13 & ss 13689 & 92 & 480 & $18: 55: 57$ & 1.07 & 1.24 & 1.22 & 1.89 & 2.01 \\
\hline $2 / 28$ & $20: 51: 34$ & ss 13719 & 119 & - & - & - & 1.01 & - & 1.97 & - \\
\hline $3 / 1$ & $21: 17: 13$ & ss 13734 & 202 & - & - & - & 1.26 & - & 1.91 & - \\
\hline $3 / 4$ & $20: 56: 26$ & ss13778 & 95 & 506 & $21: 00: 31$ & -0.07 & 1.07 & 1.13 & 1.94 & 2.05 \\
\hline $3 / 5$ & $21: 22: 04$ & ss 13793 & 64 & 423 & $20: 19: 23$ & 1.04 & 1.37 & 1.16 & 2.26 & 2.82 \\
\hline $3 / 5$ & $22: 59: 47$ & ss13794 & 445 & 695 & $20: 19: 23$ & 2.67 & 1.24 & 1.16 & 2.22 & 2.82 \\
\hline $3 / 6$ & $21: 47: 43$ & ss13808 & 63 & 357 & $19: 31: 14$ & 2.27 & 1.38 & 1.22 & 2.29 & 2.82 \\
\hline $3 / 6$ & $23: 25: 25$ & ss13809 & 497 & 631 & $19: 31: 14$ & 3.90 & 1.34 & 1.22 & 2.35 & 2.82 \\
\hline $3 / 7$ & $22: 13: 21$ & ss 13823 & 98 & 300 & $18: 27: 54$ & 3.76 & 1.33 & 1.32 & 1.95 & 2.73 \\
\hline $3 / 8$ & $22: 38: 59$ & ss 13838 & 152 & - & - & - & 1.28 & - & 2.13 & - \\
\hline $3 / 13$ & $23: 09: 33$ & ss 13912 & 357 & - & - & - & 1.77 & - & 2.43 & - \\
\hline
\end{tabular}

${ }^{a}$ Universal time of observation.

$\mathrm{b}_{\Delta_{1}}$ is distance from ACE-FTS occultation measurement to PEARL.

${ }^{\mathrm{c}} \Delta_{2}$ is distance from ACE-FTS occultation measurement to PARIS-IR observation.

$\mathrm{d}_{\Delta_{3}}$ is the difference in time between the ACE-FTS occultation measurement and the DA8 FTS observation.

e The scaled Potential Vorticity (sPV) at altitudes of $18.5 \mathrm{~km}$ and $18.0 \mathrm{~km}$ along the optical paths of the ACE-FTS and PARIS-IR, respectively.

${ }^{\mathrm{f}}$ The scaled Potential Vorticity (sPV) at altitudes of $30.5 \mathrm{~km}$ and $30.0 \mathrm{~km}$ along the optical paths of the ACE-FTS and PARIS-IR, respectively.

smoothing and partial column calculation techniques were used for all of the studies. However, these results differ in some respects from the current study because wider time ranges were used (typically February 2004 through December 2006, rather than only during spring 2006) and, in some cases, broader coincidence criteria were used (up to $1000 \mathrm{~km} ; \pm 24 \mathrm{~h}$ ). Despite these differences, our results are in reasonable agreement for all species. For example, Dupuy et al. (2009) found percentage differences between -10 and $+7 \%$ for their $\mathrm{O}_{3}$ comparisons and the DA8 FTS and PARIS-IR results ( $-5.9 \%$ and $-5.2 \%$, respectively) fall within this range. Comparisons for $\mathrm{HCl}$ and $\mathrm{HF}$, done by Mahieu et al. (2008), show average agreement between the ground-based FTS and ACE-FTS partial column densities of 

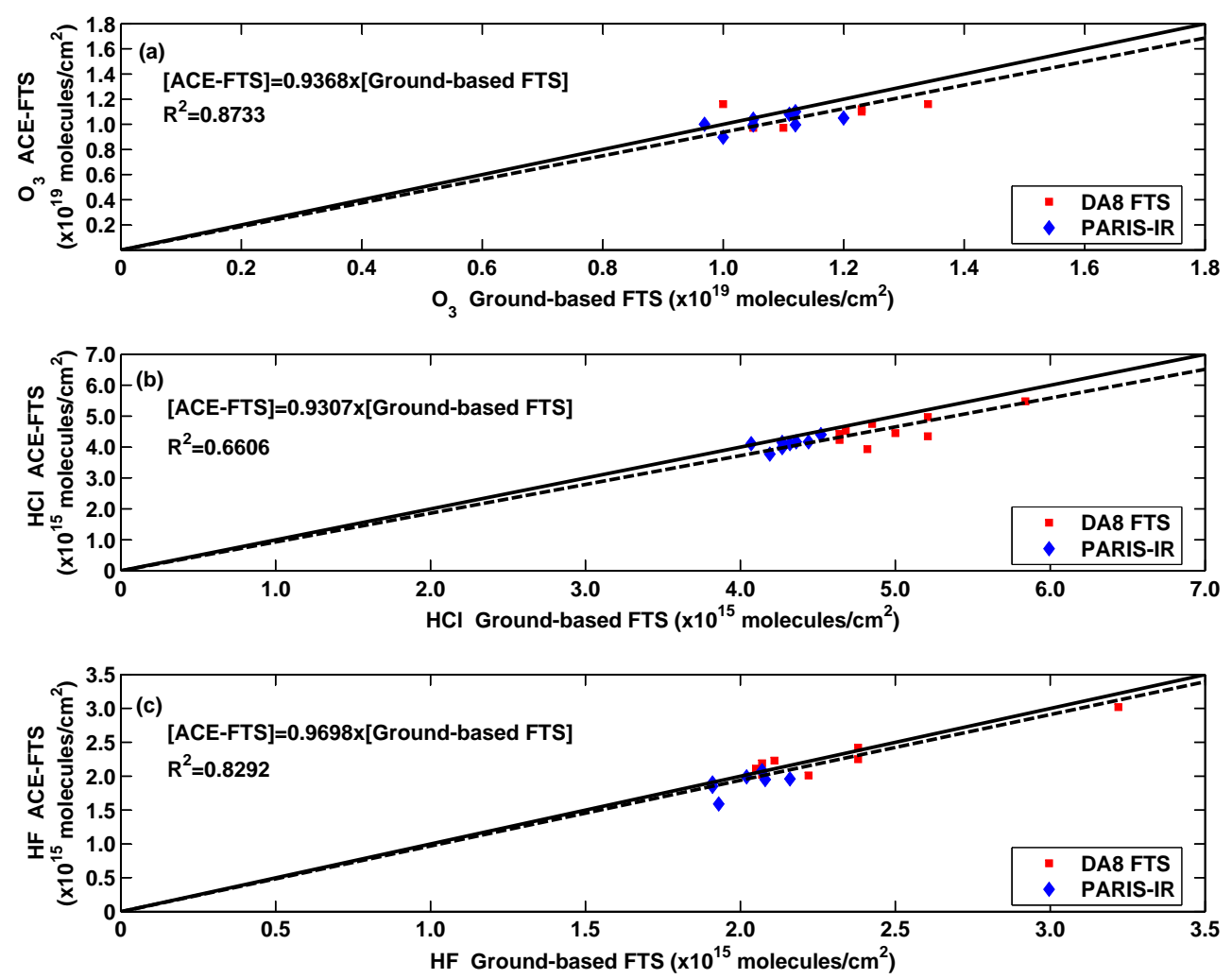

Fig. 6. Scatter plot of partial columns measured by ACE-FTS versus those observed by ground-based FTSs for (a) $\mathrm{O}_{3}$, (b) $\mathrm{HCl}$, and (c) $\mathrm{HF}$. In all figures, the dotted line shows the fitted correlation function between the two data sets being compared. Results from both the DA8 FTS and PARIS-IR were fit together in this calculation. The slope and $R^{2}$ for the comparisons are given on the figure. The solid line shows the one-to-one relationship for the comparison.

approximately $+6 \%$ and $+8 \%$, respectively. Here the differences for $\mathrm{HCl}$ and $\mathrm{HF}$ are $-4.6 \%$ and $-4.7 \%$, for PARISIR, and $-8.5 \%$ and $-0.9 \%$ for the DA8 FTS, respectively. The differences found for $\mathrm{ClONO}_{2}$ by Wolff et al. (2008) covered a wide range from $-34 \%$ to $+56 \%$ with a large standard deviation for the mean difference of $\pm 35 \%$. The mean differences and standard deviation of the differences found in this study are consistent with the work of Wolff and coworkers. For $\mathrm{HNO}_{3}$, the percentage differences found by Wolff et al. (2008) ranged from $-13 \%$ to $+6 \%$ and are consistent with the results obtained here which were differences of $-6.6 \%$ with the DA8 FTS and $+5.7 \%$ with PARIS-IR. Finally for $\mathrm{NO}_{2}$ and $\mathrm{NO}$, Kerzenmacher et al. (2008) reported differences between ground-based FTSs and ACE-FTS between $-9 \%$ and $+21 \%$ for $\mathrm{NO}_{2}$. The current results for the DA8 FTS and PARIS-IR are outside of this range $(-21.6 \%$ and $-11.9 \%$, respectively). However, the uncertainties for DA8 FTS and PARIS-IR total column retrievals are $23.0 \%$ and $25.3 \%$, respectively. During the campaign, only the DA8 FTS was able to provide NO results and these partial columns differed from ACE-FTS by $-9.9 \%$. This difference is smaller in magnitude than that found by Kerzenmacher et al., who reported differences between $-14.5 \%$ and $-67.5 \%$.
Figure 6 shows scatter plots of the ACE-FTS partial column densities versus the ground-based FTS partial column densities for $\mathrm{O}_{3}, \mathrm{HCl}$, and HF. The PARIS-IR and DA8 FTS results are both included on each plot. The plots show good correlation between the satellite and ground-based data sets. For the regression fits (shown in dotted black line), both the DA8 and PARIS-IR results were fitted together and the intercepts were set to zero because of the limited number of data points available. The fitted slopes are slightly smaller than one in all cases.

\subsection{Comparison of time evolution of trace gases during the 2006 Canadian Arctic ACE Validation Campaign}

When investigating changes in trace gas species with time, it is useful to be able to separate chemical and dynamical effects. Previous studies have used long-lived tracers such as HF, to normalize the column densities of stratospheric species in order to remove most of the dynamical effects such as diabatic descent (Toon et al., 1999; Mellqvist et al., 2002). This technique works well because the $\mathrm{O}_{3}, \mathrm{ClONO}_{2}, \mathrm{HCl}$, $\mathrm{HNO}_{3}$, and $\mathrm{HF}$ atmospheric profiles have similar shapes with peak values in the stratosphere. For this study, the total 
Table 7. The spatial and temporal differences between DA 8 and ACE-FTS observations for $\mathrm{O}_{3}, \mathrm{HNO}_{3}$, and $\mathrm{ClONO}_{2}$ during the 2006 Canadian Arctic ACE Validation Campaign.

\begin{tabular}{|c|c|c|c|c|c|c|c|c|}
\hline \multirow{3}{*}{$\begin{array}{c}\begin{array}{c}\text { Date } \\
\mathrm{mm} / \mathrm{dd}\end{array} \\
2 / 22\end{array}$} & \multirow{3}{*}{$\begin{array}{c}\begin{array}{c}\text { ACE Time } \\
\text { hh:mm:ss }\end{array} \\
21: 32: 40\end{array}$} & \multirow{3}{*}{$\begin{array}{c}\text { Occultation } \\
\text { ss13631 }\end{array}$} & \multirow{3}{*}{$\begin{array}{c}\Delta_{1}^{\mathrm{b}} \\
(\mathrm{km}) \\
449\end{array}$} & \multirow{3}{*}{$\begin{array}{c}\Delta_{2}^{\mathrm{c}} \\
(\mathrm{km}) \\
-\end{array}$} & \multirow{3}{*}{$\begin{array}{c}\text { DA8 FTS Time } \\
\text { hh:mm:ss } \\
-\end{array}$} & \multirow{3}{*}{$\begin{array}{c}\begin{array}{c}\Delta_{3}^{\mathrm{d}} \\
\text { (hours) }\end{array} \\
-\end{array}$} & \multicolumn{2}{|c|}{$\mathrm{sPV} 18 \mathrm{~km}\left(10^{-4} \mathrm{~s}^{-1}\right)^{\mathrm{e}}$} \\
\hline & & & & & & & ACE-FTS & DA8 FTS \\
\hline & & & & & & & 1.17 & - \\
\hline $2 / 23$ & $20: 20: 45$ & ss13645 & 201 & - & - & - & 0.97 & - \\
\hline $2 / 26$ & 20:00:13 & ss13689 & 92 & - & - & - & 1.24 & - \\
\hline $2 / 28$ & $20: 51: 34$ & ss13719 & 119 & - & - & - & 1.01 & - \\
\hline $3 / 1$ & $21: 17: 13$ & ss 13734 & 202 & - & - & - & 1.26 & - \\
\hline $3 / 4$ & $20: 56: 26$ & ss 13778 & 95 & $738 / 667$ & $14: 57: 23 / 15: 22: 48$ & $5.98 / 5.56$ & 1.07 & 1.13 \\
\hline $3 / 5$ & $21: 22: 04$ & ss13793 & 64 & $709 / 644$ & $14: 39: 24 / 15: 00: 41$ & $6.71 / 6.36$ & 1.37 & 1.30 \\
\hline $3 / 5$ & $22: 59: 47$ & ss13794 & 445 & $482 / 460$ & $14: 39: 24 / 15: 00: 41$ & $8.34 / 7.99$ & 1.24 & 1.30 \\
\hline $3 / 6$ & $21: 47: 43$ & ss 13808 & 63 & $456 / 428$ & $15: 54: 00 / 16: 15: 41$ & $5.90 / 5.53$ & 1.38 & 1.32 \\
\hline $3 / 6$ & $23: 25: 25$ & ss13809 & 497 & $445 / 457$ & $15: 54: 00 / 16: 15: 41$ & $7.52 / 7.16$ & 1.34 & 1.32 \\
\hline $3 / 7$ & $22: 13: 21$ & ss 13823 & 98 & 521 & $14: 42: 02$ & 7.52 & 1.33 & 1.33 \\
\hline $3 / 8$ & $22: 38: 59$ & ss 13838 & 152 & - & - & - & 1.28 & - \\
\hline $3 / 13$ & 23:09:33 & ss13912 & 357 & 257 & $17: 10: 24$ & 5.99 & 1.77 & 1.80 \\
\hline
\end{tabular}

${ }^{a}$ Universal time of observation.

${ }^{\mathrm{b}} \Delta_{1}$ is distance from ACE-FTS occultation measurement to PEARL.

${ }^{\mathrm{c}} \Delta_{2}$ is distance from ACE-FTS occultation measurement to DA8 FTS observation.

$\mathrm{d}_{\Delta_{3}}$ is the difference in time btween the ACE-FTS occultation measurement and the DA8 FTS observation.

e The scaled Potential Vorticity (sPV) at altitudes of $18.5 \mathrm{~km}$ and $18.0 \mathrm{~km}$ along the optical paths of the ACE-FTS and DA8 FTS, respectively.

Table 8. The spatial and temporal differences between DA8 and ACE-FTS for $\mathrm{HCl}$ and $\mathrm{NO}_{2}$ during the 2006 Canadian Arctic ACE Validation Campaign.

\begin{tabular}{|c|c|c|c|c|c|c|c|c|c|c|}
\hline \multirow{2}{*}{$\begin{array}{l}\text { Date } \\
\mathrm{mm} / \mathrm{dd}\end{array}$} & \multirow{2}{*}{$\begin{array}{l}\text { ACE Time }^{\mathrm{a}} \\
\text { hh:mm:ss }\end{array}$} & \multirow[t]{2}{*}{ Occultation } & \multirow{2}{*}{$\begin{array}{c}\Delta_{1}^{\mathrm{b}} \\
(\mathrm{km})\end{array}$} & \multirow{2}{*}{$\begin{array}{c}\Delta_{2}^{\mathrm{c}} \\
(\mathrm{km})\end{array}$} & \multirow{2}{*}{$\begin{array}{l}\text { DA8 FTS Time } \\
\text { hh:mm:ss }\end{array}$} & \multirow{2}{*}{$\begin{array}{c}\Delta_{3}^{\mathrm{d}} \\
\text { (hours) }\end{array}$} & \multicolumn{2}{|c|}{$\mathrm{sPV} 18 \mathrm{~km}\left(10^{-4} \mathrm{~s}^{-1}\right)^{\mathrm{e}}$} & \multicolumn{2}{|c|}{ sPV $30 \mathrm{~km}\left(10^{-4} \mathrm{~s}^{-1}\right)^{f}$} \\
\hline & & & & & & & ACE-FTS & DA8 FTS & ACE-FTS & DA8 FTS \\
\hline $2 / 22$ & $21: 32: 40$ & ss 13631 & 449 & - & - & - & 1.17 & - & 1.71 & - \\
\hline $2 / 23$ & $20: 20: 45$ & ss 13645 & 201 & $454 / 426$ & $17: 36: 15 / 17: 59: 01$ & $2.74 / 2.36$ & 0.97 & 0.98 & 1.68 & 2.12 \\
\hline $2 / 26$ & $20: 00: 13$ & ss 13689 & 92 & $486 / 502$ & $19: 28: 55 / 19: 51: 50$ & $0.52 / 0.14$ & 1.24 & 1.19 & 1.89 & 2.15 \\
\hline $2 / 28$ & $20: 51: 34$ & ss 13719 & 119 & - & - & - & 1.01 & - & 1.97 & - \\
\hline $3 / 1$ & $21: 17: 13$ & ss 13734 & 202 & - & - & - & 1.26 & - & 1.91 & - \\
\hline $3 / 4$ & $20: 56: 26$ & ss 13778 & 95 & 528 & $16: 41: 15$ & 4.25 & 1.07 & 1.19 & 1.94 & 2.15 \\
\hline $3 / 5$ & $21: 22: 04$ & ss 13793 & 64 & $580 / 532$ & $15: 26: 55 / 15: 51: 51$ & $5.92 / 5.50$ & 1.37 & 1.33 & 2.26 & 2.61 \\
\hline $3 / 5$ & $22: 59: 47$ & ss 13794 & 445 & $448 / 447$ & $15: 26: 55 / 15: 51: 51$ & $7.55 / 7.13$ & 1.24 & 1.33 & 2.22 & 2.61 \\
\hline $3 / 6$ & $21: 47: 43$ & ss 13808 & 63 & 358 & $17: 53: 33$ & 3.90 & 1.38 & 1.28 & 2.29 & 2.79 \\
\hline $3 / 6$ & $23: 25: 25$ & ss 13809 & 497 & 526 & $17: 53: 33$ & 5.53 & 1.34 & 1.28 & 2.35 & 2.79 \\
\hline $3 / 7$ & $22: 13: 21$ & ss 13823 & 98 & $457 / 415 / 382$ & $15: 08: 11 / 15: 30: 42 / 15: 53: 45$ & 7.09/6.71/6.33 & 1.33 & 1.32 & 1.95 & 2.80 \\
\hline $3 / 8$ & $22: 38: 59$ & ss 13838 & 152 & - & - & - & 1.28 & - & 2.13 & - \\
\hline $3 / 13$ & $23: 09: 33$ & ss 13912 & 357 & $193 / 178$ & $18: 37: 44 / 18: 58: 58$ & $4.53 / 4.18$ & 1.77 & 1.85 & 2.43 & 3.47 \\
\hline
\end{tabular}

${ }^{a}$ Universal time of observation.

$\mathrm{b}_{\Delta_{1}}$ is distance from ACE-FTS occultation measurement to PEARL.

${ }^{\mathrm{c}} \Delta_{2}$ is distance from ACE-FTS occultation measurement to DA8 FTS observation.

${ }^{\mathrm{d}} \Delta_{3}$ is the difference in time between the ACE-FTS occultation measurement and the DA8 FTS observation.

e The scaled Potential Vorticity (sPV) at altitudes of $18.5 \mathrm{~km}$ and $18.0 \mathrm{~km}$ along the optical paths of the ACE-FTS and DA8 FTS, respectively.

$\mathrm{f}_{\mathrm{f}}$ The scaled Potential Vorticity (sPV) at altitudes of $30.5 \mathrm{~km}$ and $30.0 \mathrm{~km}$ along the optical paths of the ACE-FTS and DA8 FTS, respectively.

columns of $\mathrm{O}_{3}, \mathrm{HCl}, \mathrm{ClONO}_{2}$, and $\mathrm{HNO}_{3}$ from PARIS-IR and the DA8 FTS were normalized by taking ratios with the total columns of HF and the results are shown in panels a-d of Fig. 7, respectively. Because the DA8 FTS cannot measure $\mathrm{ClONO}_{2}, \mathrm{HCl}, \mathrm{HNO}_{3}$, and $\mathrm{O}_{3}$ simultaneously with HF (the MWs are not in the same filter band), the daily mean total column densities were used for this investigation. For PARIS-IR, individual simultaneous measurements were used to compute the ratios and these ratios were then aver- aged to obtain the daily mean column ratios of $[\mathrm{HCl}] /[\mathrm{HF}]$, $\left[\mathrm{ClONO}_{2}\right] /[\mathrm{HF}],\left[\mathrm{HNO}_{3}\right] /[\mathrm{HF}]$, and $\left[\mathrm{O}_{3}\right] /[\mathrm{HF}]$. For the three days where there are measurements from both instruments, PARIS-IR and the DA8 FTS are in reasonable agreement and have similar trends. The same normalization procedure was also applied to the ACE-FTS partial column densities of $\mathrm{O}_{3}$, $\mathrm{ClONO}_{2}, \mathrm{HCl}, \mathrm{HNO}_{3}$ and $\mathrm{HF}$. For each species, the altitude range for the partial column ratio was chosen to match the range where retrievals were available for both the molecule 
Table 9. The spatial and temporal differences between DA8 and ACE-FTS for HF during the 2006 Canadian Arctic ACE Validation Campaign.

\begin{tabular}{|c|c|c|c|c|c|c|c|c|}
\hline \multirow{3}{*}{$\begin{array}{c}\begin{array}{c}\text { Date } \\
\mathrm{mm} / \mathrm{dd}\end{array} \\
2 / 22\end{array}$} & \multirow{3}{*}{$\begin{array}{c}\begin{array}{c}\text { ACE Time } \\
\text { hh:mm:ss }\end{array} \\
21: 32: 40\end{array}$} & \multirow{3}{*}{$\begin{array}{c}\text { Occultation } \\
\text { ss13631 }\end{array}$} & \multirow{3}{*}{$\begin{array}{c}\Delta_{1}^{\mathrm{b}} \\
(\mathrm{km})\end{array}$} & \multirow{3}{*}{$\begin{array}{c}\Delta_{2}^{\mathrm{c}} \\
(\mathrm{km}) \\
-\end{array}$} & \multirow{3}{*}{$\begin{array}{c}\text { DA8 FTS Time } \\
\text { hh:mm:ss } \\
-\end{array}$} & \multirow{3}{*}{$\begin{array}{c}\begin{array}{c}\Delta_{3}^{\mathrm{d}} \\
\text { (hours) }\end{array} \\
-\end{array}$} & \multicolumn{2}{|c|}{$\mathrm{sPV} 18 \mathrm{~km}\left(10^{-4} \mathrm{~s}^{-1}\right)^{\mathrm{e}}$} \\
\hline & & & & & & & ACE-FTS & DA8 FTS \\
\hline & & & & & & & 1.17 & - \\
\hline $2 / 23$ & $20: 20: 45$ & ss13645 & 201 & $407 / 429$ & $18: 53: 19 / 19: 22: 40$ & $1.46 / 0.97$ & 0.97 & 0.93 \\
\hline $2 / 26$ & 20:00:13 & ss 13689 & 92 & $480 / 480$ & $18: 55: 55 / 19: 10: 28$ & $1.07 / 0.83$ & 1.24 & 1.18 \\
\hline $2 / 28$ & $20: 51: 34$ & ss13719 & 119 & - & - & - & 1.01 & - \\
\hline $3 / 1$ & $21: 17: 13$ & ss 13734 & 202 & - & - & - & 1.26 & - \\
\hline $3 / 4$ & $20: 56: 26$ & ss 13778 & 95 & - & - & - & 1.07 & - \\
\hline $3 / 5$ & 21:22:04 & ss13793 & 64 & $462 / 448$ & $16: 44: 12 / 16: 59: 25$ & $4.63 / 4.38$ & 1.37 & 1.30 \\
\hline $3 / 5$ & $22: 59: 47$ & ss13794 & 445 & $465 / 472$ & $16: 44: 12 / 16: 59: 25$ & $6.26 / 6.01$ & 1.24 & 1.30 \\
\hline $3 / 6$ & $21: 47: 43$ & ss 13808 & 63 & 349 & $18: 55: 17$ & 2.87 & 1.38 & 1.24 \\
\hline $3 / 6$ & $23: 25: 25$ & ss13809 & 497 & 586 & $18: 55: 17$ & 4.50 & 1.34 & 1.24 \\
\hline $3 / 7$ & $22: 13: 21$ & ss 13823 & 98 & $354 / 339$ & $16: 18: 42 / 16: 35: 06$ & $5.91 / 5.64$ & 1.33 & 1.31 \\
\hline $3 / 8$ & $22: 38: 59$ & ss 13838 & 152 & - & - & - & 1.28 & - \\
\hline $3 / 13$ & $23: 09: 33$ & ss13912 & 357 & $163 / 153$ & $19: 22: 19 / 19: 40: 14$ & $3.79 / 3.49$ & 1.77 & 1.86 \\
\hline
\end{tabular}

${ }^{a}$ Universal time of observation.

$\mathrm{b}^{\mathrm{b}} \Delta_{1}$ is distance from ACE-FTS occultation measurement to PEARL.

$\mathrm{c}^{\mathrm{c}} \Delta_{2}$ is distance from ACE-FTS occultation measurement to DA8 FTS observation.

$\mathrm{d}_{\Delta_{3}}$ is the difference in time between the ACE-FTS occultation measurement and the DA8 FTS observation.

e The scaled Potential Vorticity (sPV) at altitudes of $18.5 \mathrm{~km}$ and $18.0 \mathrm{~km}$ along the optical paths of the ACE-FTS and DA8 FTS, respectively.

Table 10. The spatial and temporal differences between DA8 and ACE-FTS for NO during the 2006 Canadian Arctic ACE Validation Campaign.

\begin{tabular}{|c|c|c|c|c|c|c|c|c|c|c|}
\hline \multirow{2}{*}{$\begin{array}{l}\text { Date } \\
\mathrm{mm} / \mathrm{dd}\end{array}$} & \multirow{2}{*}{$\begin{array}{l}\text { ACE Time }{ }^{\mathrm{a}} \\
\text { hh:mm:ss }\end{array}$} & \multirow[t]{2}{*}{ Occultation } & \multirow{2}{*}{$\begin{array}{c}\Delta_{1}^{\mathrm{b}} \\
(\mathrm{km})\end{array}$} & \multirow{2}{*}{$\begin{array}{c}\Delta_{2}^{\mathrm{c}} \\
(\mathrm{km})\end{array}$} & \multirow{2}{*}{$\begin{array}{l}\text { DA8 FTS Time } \\
\text { hh:mm:ss }\end{array}$} & \multirow{2}{*}{$\begin{array}{c}\Delta_{3}^{\mathrm{d}} \\
\text { (hours) }\end{array}$} & \multicolumn{2}{|c|}{$\mathrm{sPV} 18 \mathrm{~km}\left(10^{-4} \mathrm{~s}^{-1}\right)^{\mathrm{e}}$} & \multicolumn{2}{|c|}{$\mathrm{sPV} 30 \mathrm{~km}\left(10^{-4} \mathrm{~s}^{-1}\right)^{\mathrm{f}}$} \\
\hline & & & & & & & ACE-FTS & DA8 FTS & ACE-FTS & DA8 FTS \\
\hline $2 / 22$ & $21: 32: 40$ & ss 13631 & 449 & - & - & - & 1.17 & - & 1.71 & - \\
\hline $2 / 23$ & $20: 20: 45$ & ss 13645 & 201 & - & - & - & 0.97 & - & 1.68 & - \\
\hline $2 / 26$ & $20: 00: 13$ & ss 13689 & 92 & - & - & - & 1.24 & - & 1.89 & - \\
\hline $2 / 28$ & $20: 51: 34$ & ss13719 & 119 & - & - & - & 1.01 & - & 1.97 & - \\
\hline $3 / 1$ & $21: 17: 13$ & ss13734 & 202 & - & - & - & 1.26 & - & 1.91 & - \\
\hline $3 / 4$ & $20: 56: 26$ & ss 13778 & 95 & $\begin{array}{l}452 / \\
442\end{array}$ & $\begin{array}{c}18: 14: 04 / \\
18: 37: 37\end{array}$ & $\begin{array}{l}2.71 / \\
2.31\end{array}$ & 1.07 & 1.17 & 1.94 & 2.15 \\
\hline $3 / 5$ & $21: 22: 04$ & ss 13793 & 64 & $\begin{array}{l}400 / \\
396 / \\
394 / \\
393\end{array}$ & $\begin{array}{l}18: 21: 19 / \\
18: 35: 29 / \\
18: 50: 54 / \\
19: 05: 27\end{array}$ & $\begin{array}{l}3.01 / \\
2.78 / \\
2.52 / \\
2.28\end{array}$ & 1.37 & 1.23 & 2.26 & 2.84 \\
\hline $3 / 5$ & $22: 59: 47$ & ss13794 & 445 & $\begin{array}{l}531 / \\
544 / \\
560 / \\
577\end{array}$ & $\begin{array}{c}18: 21: 19 / \\
18: 35: 29 / \\
18: 50: 54 / \\
19: 05: 27\end{array}$ & $\begin{array}{l}4.64 / \\
4.41 / \\
4.15 / \\
3.91\end{array}$ & 1.24 & 1.23 & 2.22 & 2.84 \\
\hline $3 / 6$ & $21: 47: 43$ & ss 13808 & 63 & 351 & $18: 19: 15$ & 3.47 & 1.38 & 1.26 & 2.29 & 2.80 \\
\hline $3 / 6$ & $23: 25: 25$ & ss13809 & 497 & 548 & $18: 19: 15$ & 5.10 & 1.34 & 1.26 & 2.35 & 2.80 \\
\hline $3 / 7$ & $22: 13: 21$ & ss 13823 & 98 & 300 & $18: 27: 44$ & 3.76 & 1.33 & 1.32 & 1.95 & 2.73 \\
\hline $3 / 8$ & $22: 38: 59$ & ss13838 & 152 & - & - & - & 1.28 & - & 2.13 & - \\
\hline $3 / 13$ & $23: 09: 33$ & ss13912 & 357 & $\begin{array}{l}214 / \\
204\end{array}$ & $\begin{array}{c}18: 07: 43 / \\
18: 21: 55\end{array}$ & $\begin{array}{l}5.03 / \\
4.79\end{array}$ & 1.77 & 1.84 & 2.43 & 3.45 \\
\hline
\end{tabular}

a Universal time of observation.

${ }^{\mathrm{b}} \Delta_{1}$ is distance from ACE-FTS occultation measurement to PEARL.

${ }^{\mathrm{c}} \Delta_{2}$ is distance from ACE-FTS occultation measurement to DA8 FTS observation.

$\mathrm{d}_{\Delta_{3}}$ is the difference in time between the ACE-FTS occultation measurement and the DA8 FTS observation.

e The scaled Potential Vorticity (sPV) at altitudes of $18.5 \mathrm{~km}$ and $18.0 \mathrm{~km}$ along the optical paths of the ACE-FTS and DA8 FTS, respectively.

$\mathrm{f}_{\mathrm{f}}$ The scaled Potential Vorticity (sPV) at altitudes of $30.5 \mathrm{~km}$ and $30.0 \mathrm{~km}$ along the optical paths of the ACE-FTS and DA8 FTS, respectively. 

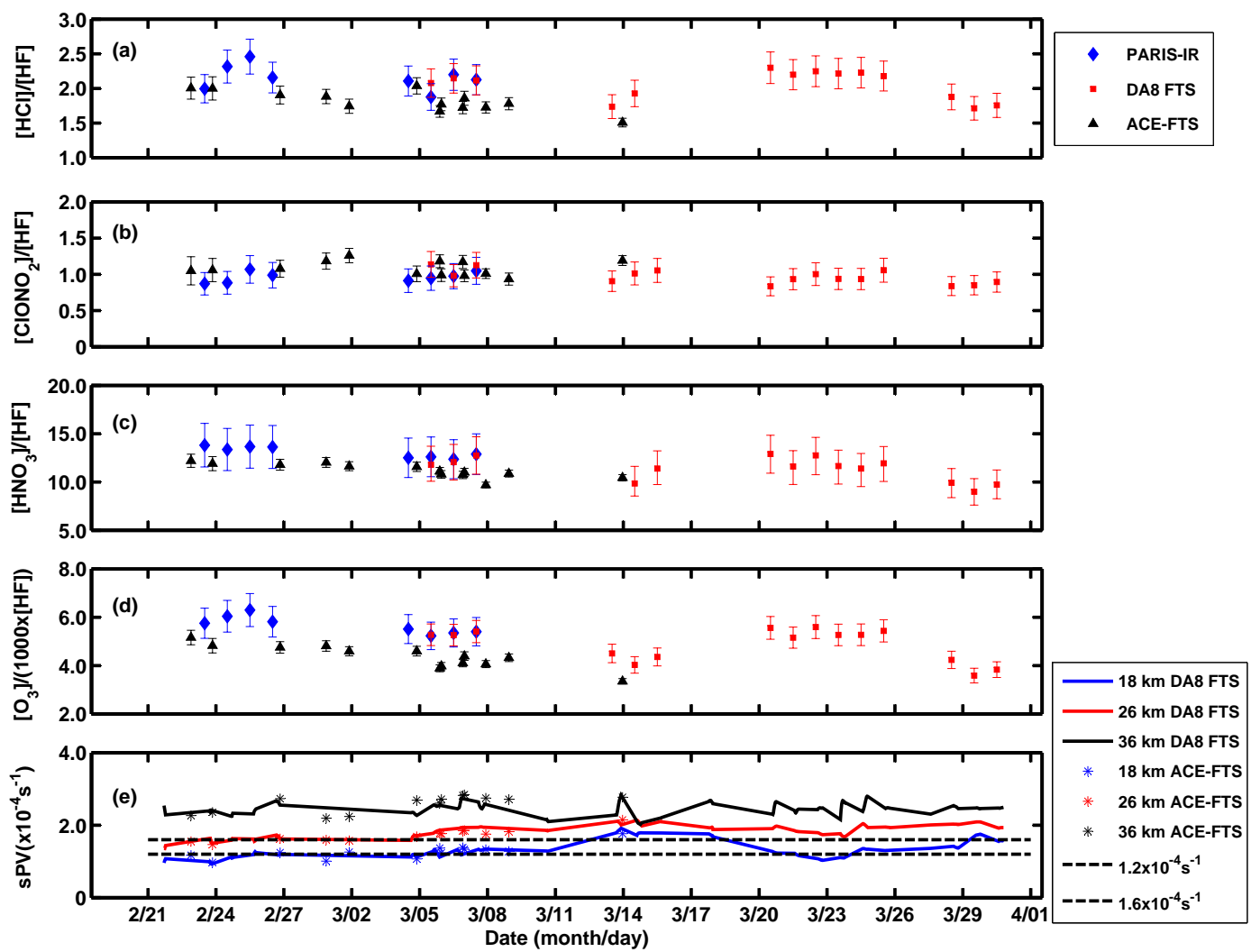

Fig. 7. Time evolution of total column density ratio for $\mathrm{HCl}$ (a), $\mathrm{ClONO}_{2}$ (b), $\mathrm{HNO}_{3}$ (c), and $\mathrm{O}_{3}$ (d), normalized with $\mathrm{HF}$ from the observations using PARIS-IR (blue diamonds) and the DA8 FTS (red squares) during the 2006 Canadian Arctic ACE Validation Campaign. The partial column density ratios calculated from the ACE-FTS results are also shown (black triangles). The altitude ranges of the partial column density ratios of $[\mathrm{HCl}] /[\mathrm{HF}],\left[\mathrm{ClONO}_{2}\right] /[\mathrm{HF}],\left[\mathrm{HNO}_{3}\right] /[\mathrm{HF}]$, and $\left[\mathrm{O}_{3}\right] /[\mathrm{HF}]$ from ACE-FTS are 13.5-44.5 km, 14.5-30.5 km, 13.5$31.5 \mathrm{~km}$ and $13.5-44.5 \mathrm{~km}$, respectively. The altitude range of the total column density ratios from the DA8 FTS and PARIS-IR is surface $100 \mathrm{~km}$. (e) The scaled potential vorticity (sPV) at altitudes of $18 \mathrm{~km}, 26 \mathrm{~km}$ and $36 \mathrm{~km}$ along the optical paths of the DA8 FTS measurements and those of ACE-FTS from GEOS-4 analyses. The dashed lines indicate 1.2 and $1.6 \times 10^{-4} \mathrm{~s}^{-1}$, the edges of the polar vortex. Error bars for the ratios are calculated by propagating the error in the total column densities given in Table 2 for the DA8 FTS and PARIS-IR, and the spectral fitting error for the ACE-FTS partial column densities.

and HF. The ACE-FTS partial column density ratios are expected to have an offset from those obtained from the groundbased FTSs because the satellite profiles were truncated in the lowermost stratosphere due to the altitude range available for the ACE-FTS HF data. The results for ACE-FTS and the ground-based spectrometers appear to have similar trends.

The time evolution of the ratios, $[\mathrm{HCl}] /[\mathrm{HF}]$, $\left[\mathrm{ClONO}_{2}\right] /[\mathrm{HF}], \quad\left[\mathrm{HNO}_{3}\right] /[\mathrm{HF}]$, and $\left[\mathrm{O}_{3}\right] /[\mathrm{HF}]$, is consistent with the region of the polar vortex that is sampled by these measurements. For this discussion, we will use the $\mathrm{sPV}$ values at $18 \mathrm{~km}$ because the maximum number density of all of these species is near this altitude (for the Arctic at this time of year). These values are shown in panel e of Fig. 7. Based on SPV at $18 \mathrm{~km}$, the ground-based campaign measurements can be divided between those primarily inside the vortex (13-16 March and 28-31 March) and those primarily near the edge or outside of the vortex (21 February-11 March and 20-26 March). This clas- sification corresponds to air masses having $\mathrm{SPV}$ values greater or less than $1.6 \times 10^{-4} \mathrm{~s}^{-1}$. For $\mathrm{HCl}, \mathrm{HNO}_{3}$ and $\mathrm{O}_{3}$, the ratios inside the vortex are slightly lower than those outside and on the edge of the vortex as is expected in polar springtime. The $\mathrm{ClONO}_{2}$ ratio values obtained for the inside and outside/edge regions are more similar. To look at the correlation more closely, the ratio of $\left[\mathrm{O}_{3}\right] /[\mathrm{HF}]$ has been plotted versus $[\mathrm{HCl}] /[\mathrm{HF}],\left[\mathrm{HCl}+\mathrm{ClONO}_{2}\right] /[\mathrm{HF}]$, and $\left[\mathrm{HNO}_{3}\right] /[\mathrm{HF}]$ in panels a-c of Fig. 8. For this similar air mass, the column ratios show changes of about $50 \%$ during the entire campaign.

The partitioning of chlorine during the 2006 Arctic vortex has been investigated using measurements from two satellite instruments, the Microwave Limb Sounder (MLS) on Aura and ACE-FTS on SCISAT, and the SLIMCAT three-dimensional chemical transport model (Santee et al., 2008). They found that the SSW in mid-January essentially caused chemical processing in the vortex to end and 

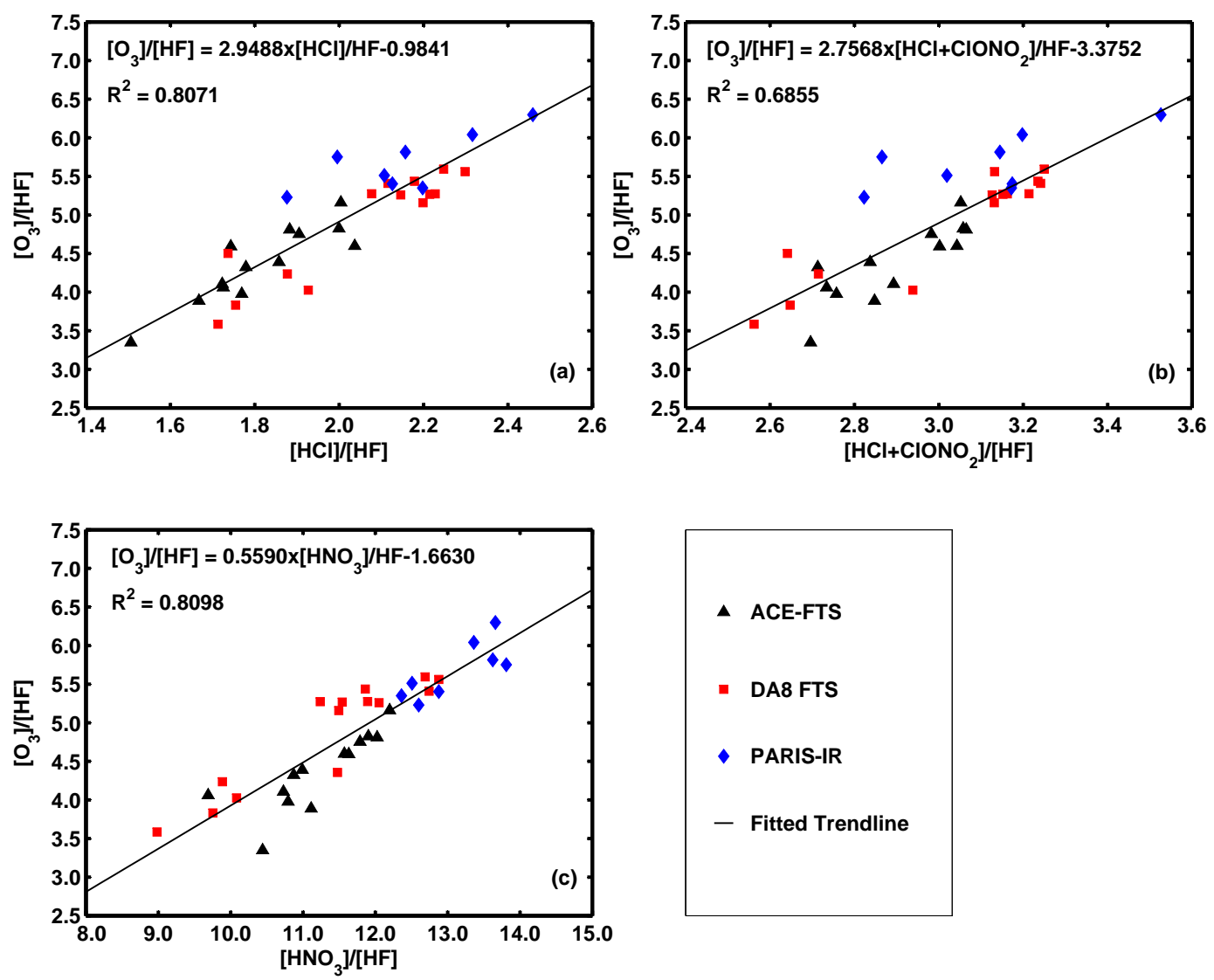

Fig. 8. Scatter plot of (a) partial column ratio of $[\mathrm{HCl}] /[\mathrm{HF}]$ vs. $\left[\mathrm{O}_{3}\right] /[\mathrm{HF}]$ from ACE-FTS (black triangles) along with total column ratios of $[\mathrm{HCl}] /[\mathrm{HF}]$ vs. $\left[\mathrm{O}_{3}\right] /[\mathrm{HF}]$ from PARIS-IR (blue diamonds) and the DA8 FTS (red squares). (b) Same as (a), but for $[\mathrm{HCl}+\mathrm{ClONO} 2] /[\mathrm{HF}]$ vs. $\left[\mathrm{O}_{3}\right] /[\mathrm{HF}]$. (c) Same as (a), but for $\left[\mathrm{HNO}_{3}\right] /[\mathrm{HF}]$. The altitude ranges of the partial column density ratios of $[\mathrm{HCl}] /[\mathrm{HF}],[\mathrm{ClONO} 2] /[\mathrm{HF}]$, $\left[\mathrm{HNO}_{3}\right] /[\mathrm{HF}]$, and $\left[\mathrm{O}_{3}\right] /[\mathrm{HF}]$ from ACE-FTS are $13.5-44.5 \mathrm{~km}, 14.5-30.5 \mathrm{~km}, 13.5-31.5 \mathrm{~km}$ and $13.5-44.5 \mathrm{~km}$, respectively. The altitude ranges of the total column density ratios from the DA8 FTS and PARIS-IR are surface $-100 \mathrm{~km}$. In all figures, the solid line indicates the fitted correlation between $\mathrm{x}$ and y domains. The correlation function and $R^{2}$ are given on the figure.

chlorine deactivation to begin. This can be seen in Fig. 6 of Santee et al. which shows the time series of vortex average $\mathrm{HCl}, \mathrm{ClONO}_{2}$, and $\mathrm{ClO}$ at the $520 \mathrm{~K}$ potential temperature level for four $5^{\circ}$-wide equivalent latitude bands from $65^{\circ}$ to $80^{\circ}$. By the beginning of the ground-based FTS measurements in late February, chlorine deactivation within the vortex was nearly complete and there were thus no rapid or significant changes in $\mathrm{HCl}$ and $\mathrm{ClONO}_{2}$ VMRs observed at Eureka throughout the six weeks of the campaign. For the inside the vortex measurements, this relatively constant behaviour is what was seen in the ground-based FTS ratios of $\mathrm{HCl}$ and $\mathrm{ClONO}_{2}$ with $\mathrm{HF}$ from PEARL (Fig. 7). Similarly, within the vortex, there was no rapid change in $\mathrm{O}_{3}$ VMR, and the $\mathrm{HNO}_{3}$ VMR was observed to decline slowly by MLS and ACE-FTS from late February to the end of March (e.g., Fig. 7 in Santee et al., 2008). This behaviour can be seen in the PARIS-IR and DA8 FTS $\mathrm{O}_{3}$ in-vortex results. However, it is difficult to discern a trend in $\mathrm{HNO}_{3}$ from the relatively few points obtained within the vortex from the ground-based
FTS measurements. For those ground-based FTS measurements taken within or near the edge of the vortex, there appears to be a small decrease in the ratios of $\mathrm{O}_{3}, \mathrm{HNO}_{3}$ and $\mathrm{HCl}$ over the campaign period whereas the $\mathrm{ClONO}_{2}$ does not show as significant a change.

\section{Summary and conclusions}

The 2006 Canadian Arctic ACE Validation Campaign made measurements for the Atmospheric Chemistry Experiment (ACE) satellite mission at PEARL, Eureka from 17 February until 31 March in 2006. The DA8 FTS and PARIS-IR observations were performed simultaneously so that instrument performance could be compared directly. The solar beam was shared between the two FTSs and spectral co-additions were performed over the same time intervals to ensure simultaneity. From these spectra, vertical total columns and partial columns of $\mathrm{O}_{3}, \mathrm{ClONO}_{2}, \mathrm{HCl}, \mathrm{HNO}_{3}, \mathrm{NO}, \mathrm{NO}_{2}$, and $\mathrm{HF}$ were retrieved using the SFIT2 program (version 
3.91). Mean differences in total column densities of $\mathrm{O}_{3}$, $\mathrm{HCl}, \mathrm{ClONO}_{2}, \mathrm{HF}, \mathrm{HNO}_{3}$, and $\mathrm{NO}_{2}$ from the observations between PARIS-IR and the DA8 FTS are $2.8 \%,-3.2 \%$, $-4.3 \%,-1.5 \%,-1.9 \%$, and $-0.1 \%$, respectively. These differences are comparable to those seen in earlier intercomparison studies for both instruments. By using the same analysis program, spectroscopic parameters, spectral regions, and a priori information to analyze the spectra recorded by PARIS-IR and the DA8 FTS, these differences can be taken to be due to instrumental differences such as spectral resolution.

The ground-based observations using the DA8 FTS and PARIS-IR were compared with the version 2.2 (plus updates) results from the ACE-FTS satellite instrument using partial column densities. Mean differences in partial column densities of $\mathrm{O}_{3}, \mathrm{HCl}, \mathrm{ClONO}_{2}, \mathrm{HF}, \mathrm{HNO}_{3}, \mathrm{NO}_{2}$, and $\mathrm{NO}$ from the measurements between ACE-FTS and the DA8 FTS are $-5.9 \%,-8.5 \%,-11.8 \%,-0.9 \%,-6.6 \%,-21.6 \%$ and $-7.6 \%$, respectively. Mean differences in partial column densities of $\mathrm{O}_{3}, \mathrm{HCl}, \mathrm{ClONO}_{2}, \mathrm{HF}, \mathrm{HNO}_{3}, \mathrm{NO}_{2}$ from the measurements between ACE-FTS and the PARIS-IR are $-5.2 \%,-4.6 \%,-2.3 \%,-4.7 \%, 5.7 \%$ and $-11.9 \%$, respectively. The results from PARIS-IR in general agree better with the ACE-FTS than those from the DA8 FTS for all of the investigated species. This has been attributed to better temporal coincidence with ACE-FTS observations for PARIS-IR than for the DA8 FTS measurements. Ground-based partial column results agree with the ACE-FTS partial column results to within the uncertainty estimated for the DA8 FTS and PARIS-IR and the results are consistent with those found in the other ACE-FTS version 2.2 validation studies. To verify that the air masses measured by each of the instruments in these comparisons were similar, the tangent points (for satellite) and ground locations (for ground-based measurements) of the altitudes with the maximum number density for the species of interest were calculated geometrically and the scaled potential vorticity at these levels were compared. This method provided an additional verification that the comparisons were valid.

The results from the three FTSs (ACE-FTS, PARIS-IR, and the DA8 FTS) were compared to examine the consistency in the time evolution observed for the chemical constituents in the atmosphere over Eureka during spring 2006. For this investigation, the effects of subsidence were removed by normalizing the column densities using the longlived tracer HF. There were no significant changes observed in $\mathrm{O}_{3}, \mathrm{HCl}, \mathrm{ClONO}_{2}$, and $\mathrm{HNO}_{3}$ amounts recorded inside the polar vortex during the campaign. These observations are generally consistent with the results of Santee et al. (2008), who showed that chemical processing within the polar vortex in spring 2006 had nearly ceased by the beginning of the campaign at Eureka.
Acknowledgements. The Canadian Arctic ACE Validation Campaign project has been supported by the Canadian Space Agency (CSA), Environment Canada (EC), the Natural Sciences and Engineering Research Council (NSERC) of Canada, and the Northern Scientific Training Program. Logistical and on-site technical support for the 2006 campaign was provided by the Canadian Network for the Detection of Atmospheric Change (CANDAC). CANDAC and PEARL are funded by the Canadian Foundation for Climate and Atmospheric Sciences, NSERC, the Canadian Foundation for Innovation, the Ontario Innovation Trust, the Ontario Ministry of Research and Innovation, and the Nova Scotia Research and Innovation Trust. The authors wish to thank J. Davies at Environment Canada for processing and providing the ozonesonde profiles and the Eureka Weather Station staff for their hospitality, for providing radiosonde profiles for the analyses and for launching the additional ozonesondes during the campaign. The Atmospheric Chemistry Experiment is mainly supported by CSA and NSERC. Work at the Jet Propulsion Laboratory, California Institute of Technology, was done under contract with the National Aeronautics and Space Administration.

Edited by: T. Wagner

\section{References}

Bernath, P. F., McElroy, C. T., Abrams, M. C., Boone, C. D., Butler, M., Camy-Peyret, C., Carleer, M., Clerbaux, C., Coheur, P.-F., Colin, R., DeCola, P., DeMazière, M., Drummond, J. R., Dufour, D., Evans, W. F. J., Fast, H., Fussen, D., Gilbert, K., Jennings, D. E., Llewellyn, E. J., Lowe, R. P., Mahieu, E., McConnell, J. C., McHugh, M., McLeod, S. D., Michaud, R., Midwinter, C., Nassar, R., Nichitiu, F., Nowlan, C., Rinsland, C. P., Rochon, Y. J., Rowlands, N., Semeniuk, K., Simon, P., Skelton, R., Sloan, J. J., Soucy, M.-A., Strong, K., Tremblay, P., Turnbull, D., Walker, K. A., Walkty, I., Wardle, D. A., Wehrle, V., Zander, R., and Zou, J.: Atmospheric Chemistry Experiment (ACE): Mission Overview, Geophys. Res. Lett., 32, L15S01, doi:10.1029/2005GL022386, 2005.

Bernath, P. F.: Atmospheric Chemistry Experiment (ACE): analytical chemistry from orbit, Trends Anal. Chem., 25, 647-654, 2006.

Bloom, S., da Silva, A., Dee, D., et al.: The Goddard Earth Observing Data Assimilation System, GEOS DAS Version 4.0.3: Documentation and Validation, Tech. Rep. 104606 V26, NASA, 2005.

Boone, C. D., Nassar, R., Walker, K. A., Rochon, Y., McLeod, S. D., Rinsland, C. P., and Bernath, P. F.: Retrievals for the atmospheric chemistry experiment Fourier transform spectrometer, Appl. Opt., 44, 7218-7231, 2005.

Clerbaux, C., George, M., Turquety, S., Walker, K. A., Barret, B., Bernath, P., Boone, C., Borsdorff, T., Cammas, J. P., Catoire, V., Coffey, M., Coheur, P.-F., Deeter, M., De Mazière, M., Drummond, J., Duchatelet, P., Dupuy, E., de Zafra, R., Eddounia, F., Edwards, D. P., Emmons, L., Funke, B., Gille, J., Griffith, D. W. T., Hannigan, J., Hase, F., Höpfner, M., Jones, N., Kagawa, A., Kasai, Y., Kramer, I., Le Flochmoën, E., Livesey, N. J., López-Puertas, M., Luo, M., Mahieu, E., Murtagh, D., Néélec, P., Pazmino, A., Pumphrey, H., Ricaud, P., Rinsland, C. 
P., Robert, C., Schneider, M., Senten, C., Stiller, G., Strandberg, A., K. Strong, Sussmann, R., Thouret, V., Urban, J., and Wiacek, A.: CO measurements from the ACE-FTS satellite instrument: data analysis and validation using ground-based, airborne and spaceborne observations, Atmos. Chem. Phys., 8, 2569-2594, 2008,

http://www.atmos-chem-phys.net/8/2569/2008/.

Cortesi, U., Lambert, J. C., De Clercq, C., Bianchini, G., Blumenstock, T., Bracher, A., Castelli, E., Catoire, V., Chance, K. V., De Mazière, M., Demoulin, P., Godin-Beekmann, S., Jones, N., Jucks, K., Keim, C., Kerzenmacher, T., Kuellmann, H., Kuttippurath, J., Iarlori, M., Liu, G. Y., Liu, Y., McDermid, I. S., Meijer, Y. J., Mencaraglia, F., Mikuteit, S., Oelhaf, H., Piccolo, C., Pirre, M., Raspollini, P., Ravegnani, F., Reburn, W. J., Redaelli, G., Remedios J. J, Sembhi, H., Smale, D., Steck, T., Taddei, A., Varotsos, C., Vigouroux, C., Waterfall, A., Wetzel, G., and Wood, S.: Geophysical validation of MIPAS-ENVISAT operational ozone data, Atmos. Chem. Phys., 7, 4807-4867, 2007, http://www.atmos-chem-phys.net/7/4807/2007/.

Davies, J., Tarasick, D. W., McElroy, C. T., Kerr, J. B., Fogal, P. F., and Savastiouk, V.: Evaluation of ECC Ozonesonde Preparation Methods from Laboratory Tests and Field Comparisons during MANTRA, Proceedings of the Quadrennial Ozone Symposium, Hokkaido University, Sapporo, Japan, 3-8 July 2000, edited by: Bojkov, R. D. and Kazuo, S., 137-138, 2000.

De Mazière, M., Vigouroux, C., Bernath, P. F., Baron, P., Blumenstock, T., Boone, C., Brogniez, C., Catoire, V., Coffey, M., Duchatelet, P., Griffith, D., Hannigan, J., Kasai, Y., Kramer, I., Jones, N., Mahieu, E., Manney, G. L., Piccolo, C., Randall, C., Robert, C., Senten, C., Strong, K., Taylor, J., Tétard, C., Walker, K. A., and Wood, S.: Validation of ACE-FTS v2.2 methane profiles from the upper troposphere to the lower mesosphere, Atmos. Chem. Phys., 8, 2421-2435, doi:10.5194/acp-8-2421-2008, 2008.

Donovan, D. P., Fast, H., Makino, Y., Bird, J. C., Carswell, A. I., Davies, J., Duck, T. J., Kaminski, J. W., McElroy, C. T., and Mittermeier, R. L.: Ozone, Column ClO, and PSC measurements made at the NDSC Eureka observatory $\left(80^{\circ} \mathrm{N}, 86^{\circ} \mathrm{W}\right)$ during the spring of 1997, Geophys. Res. Lett., 24, 2709-2712, 1997.

Dunkerton, T. J. and Delisi, D. P.: Evolution of potential vorticity in the winter stratosphere of January-February 1979, J. Geophys. Res., 91, 1199-1208, 1986.

Dupuy, E., Walker, K. A., Kar, J., Boone, C. D., McElroy, C. T., Bernath, P. F., Drummond, J. R., Skelton, R., McLeod, S. D., Hughes, R. C., Nowlan, C. R., Dufour, D. G., Zou, J., Nichitiu, F., Strong, K., Baron, P., Bevilacqua, R. M., Blumenstock, T., Bodeker, G. E., Borsdorff, T., Bourassa, A. E., Bovensmann, H., Boyd, I. S., Bracher, A., Brogniez, C., Burrows, J. P., Catoire, V., Ceccherini, S., Chabrillat, S., Christensen, T., Coffey, M. T., Cortesi, U., Davies, J., De Clercq, C., Degenstein, D. A., De Mazière, M., Demoulin, P., Dodion, J., Firanski, B., Fischer, H., Forbes, G., Froidevaux, L., Fussen, D., Gerard, P., GodinBeekmann, S., Goutail, F., Granville, J., Griffith, D., Haley, C. S., Hannigan, J. W., Höpfner, M., Jin, J. J., Jones, A., Jones, N. B., Jucks, K., Kagawa, A., Kasai, Y., Kerzenmacher, T. E., Kleinböhl, A., Klekociuk, A. R., Kramer, I., Küllmann, H., Kuttippurath, J., Kyrl, E., Lambert, J.-C., Livesey, N. J., Llewellyn, E. J., Lloyd, N. D., Mahieu, E., Manney, G. L., Marshall, B. T., McConnell, J. C., McCormick, M. P., McDermid, I. S., McHugh,
M., McLinden, C. A., Mellqvist, J., Mizutani, K., Murayama, Y., Murtagh, D. P., Oelhaf, H., Parrish, A., Petelina, S. V., Piccolo, C., Pommereau, J.-P., Randall, C. E., Robert, C., Roth, C., Schneider, M., Senten, C., Steck, T., Strandberg, A., Strawbridge, K. B., Sussmann, R., Swart, D. P. J., Tarasick, D. W., Taylor, J. R., Tétard, C., Thomason, L. W., Thompson, A. M., Tully, M. B., Urban, J., Vanhellemont, F., Vigouroux, C., von Clarmann, T., von der Gathen, P., von Savigny, C., Waters, J. W., Witte, J. C., Wolff, M., and Zawodny, J. M.: Validation of ozone measurements from the Atmospheric Chemistry Experiment (ACE), Atmos. Chem. Phys., 9, 287-343, doi:10.5194/acp9-287-2009, 2009.

Farahani, E., Fast, H., Mittermeier, R. L., Makino, Y., Strong, K., McLandress, C., Shepherd, T. G., Chipperfield, M. P., Hannigan, J. W., Coffey, M. T., Mikuteit, S., Hase, F., Blumenstock, T., and Raffalski, U.: Nitric acid measurements at Eureka obtained in winter 2001-2002 using solar and lunar Fourier transform infrared absorption spectroscopy: Comparisons with observations at Thule and Kiruna and with results from three-dimensional models, J. Geophys. Res., 112, D01305, doi:10.1029/2006JD007096, 2007.

Fraser, A., Goutail, F., Strong, K., Bernath, P. F., Boone, C., Daffer, W. H., Drummond, J. R., Dufour, D. G., Kerzenmacher, T. E., Manney, G. L., McElroy, C. T., Midwinter, C., McLinden, C. A., Nichitiu, F., Nowlan, C. R., Walker, J., Walker, K. A., $\mathrm{Wu}, \mathrm{H}$., and Zou, J.: Intercomparison of UV-visible measurements of ozone and $\mathrm{NO}_{2}$ during the Canadian Arctic ACE validation campaigns: 2004-2006, Atmos. Chem. Phys., 8, 1763-1788, doi:10.5194/acp-8-1763-2008, 2008.

Fu, D., Walker, K. A., Sung, K., Boone, C. D., Soucy, M.-A., and Bernath, P. F.: The Portable Atmospheric Research Interferometric Spectrometer for the Infrared, PARIS-IR, J. Quant. Spectrosc. Radiat. Transfer, 103, 362-370, 2007.

Gallery, W. O., Kneizys F. X., and Clough, S. A.: Air mass computer program for atmospheric transmittance/radiance calculation: FSCATM, Environ. Res. Pap., 828 (AFGL-TR-83-0065), U.S. Air Force Geophysics Laboratory, Bedford, Massachusetts, 1983.

Grooß, J.-U. and Russell III, James M.: Technical note: A stratospheric climatology for $\mathrm{O}_{3}, \mathrm{H}_{2} \mathrm{O}, \mathrm{CH}_{4}, \mathrm{NO}_{\mathrm{x}}, \mathrm{HCl}$ and $\mathrm{HF}$ derived from HALOE measurements, Atmos. Chem. Phys., 5, 2797-2807, doi:10.5194/acp-5-2797-2005, 2005.

Harvey, V. L. and Hitchman, M. H.: A climatology of the Aleutian high, J. Atmos. Sci., 53, 2088-2101, 1996.

Hase, F., Blumenstock, T., and Paton-Walsh, C.: Analysis of the instrumental line shape of high-resolution Fourier transform IR spectrometers with gas cell measurements and new retrieval software, Appl. Opt., 38, 3417-3422, 1999.

Höpfner, M., von Clarmann, T., Fischer, H., Funke, B., Glatthor, N., Grabowski, U., Kellmann, S., Kiefer, M., Linden, A., Milz, M., Steck, T., Stiller, G. P., Bernath, P., Blom, C. E., Blumenstock, Th., Boone, C., Chance, K., Coffey, M. T., Friedl-Vallon, F., Griffith, D., Hannigan, J. W., Hase, F., Jones, N., Jucks, K. W., Keim, C., Kleinert, A., Kouker, W., Liu, G. Y., Mahieu, E., Mellqvist, J., Mikuteit, S., Notholt, J., Oelhaf, H., Piesch, C., Reddmann, T., Ruhnke, R., Schneider, M., Strandberg, A., Toon, G., Walker, K. A., Warneke, T., Wetzel, G., Wood, S., and Zander, R.: Validation of MIPAS $\mathrm{ClONO}_{2}$ measurements, Atmos. Chem. Phys., 7, 257-281, doi:10.5194/acp-7-257-2007, 2007. 
Kalnay, E., Kanamitsu, M., Kistler, R., Collins, W., Deaven, D., Gandin, L., Iredell, M., Saha, S., White, G., Woollen, J., Zhu, Y., Leetmaa, A., Reynolds, B., Chelliah, M., Ebisuzaki, W., Higgins, W., Janowiak, J., Mo, K., Ropelewski, C., Wang, J., Jenne, R., and Joseph, D.: The NCEP/NCAR 40-year reanalysis project, Bull. Am. Meteor. Soc., 77, 437-471, 1996.

Kerzenmacher, T. E., Walker, K. A., Strong, K., Berman, R., Bernath, P. F., Boone, C. D., Drummond, J. R., Fast, H., Fraser, A., MacQuarrie, K., Midwinter, C., Sung, K., McElroy, C. T., Mittermeier, R. L., Walker, J., and Wu, H.: Measurements of $\mathrm{O}_{3}, \mathrm{NO}_{2}$ and Temperature during the 2004 Canadian Arctic ACE Validation Campaign, Geophys. Res. Lett., 32, L16S07, doi:10.1029/2005GL023032, 2005.

Kerzenmacher, T., Wolff, M. A., Strong, K., Dupuy, E., Walker, K. A., Amekudzi, L. K., Batchelor, R. L., Bernath, P. F., Berthet, G., Blumenstock, T., Boone, C. D., Bramstedt, K., Brogniez, C., Brohede, S., Burrows, J. P., Catoire, V., Dodion, J., Drummond, J. R., Dufour, D. G., Funke, B., Fussen, D., Goutail, F., Griffith, D. W. T., Haley, C. S., Hendrick, F., Höpfner, M., Huret, N., Jones, N., Kar, J., Kramer, I., Llewellyn, E. J., López-Puertas, M., Manney, G., McElroy, C. T., McLinden, C. A., Melo, S., Mikuteit, S., Murtagh, D., Nichitiu, F., Notholt, J., Nowlan, C., Piccolo, C., Pommereau, J.-P., Randall, C., Raspollini, P., Ridolfi, M., Richter, A., Schneider, M., Schrems, O., Silicani, M., Stiller, G. P., Taylor, J., Tétard, C., Toohey, M., Vanhellemont, F., Warneke, T., Zawodny, J. M., and Zou, J.: Validation of $\mathrm{NO}_{2}$ and NO from the Atmospheric Chemistry Experiment (ACE), Atmos. Chem. Phys., 8, 5801-5841, doi:10.5194/acp-8-5801-2008, 2008.

Mahieu, E., Duchatelet, P., Demoulin, P., Walker, K. A., Dupuy, E., Froidevaux, L., Randall, C., Catoire, V., Strong, K., Boone, C. D., Bernath, P. F., Blavier, J.-F., Blumenstock, T., Coffey, M., De Mazière, M., Griffith, D., Hannigan, J., Hase, F., Jones, N., Jucks, K. W., Kagawa, A., Kasai, Y., Mebarki, Y., Mikuteit, S., Nassar, R., Notholt, J., Rinsland, C. P., Robert, C., Schrems, O., Senten, C., Smale, D., Taylor, J., Tétard, C., Toon, G. C., Warneke, T., Wood, S. W., Zander, R., and Servais, C.: Validation of ACE-FTS v2.2 measurements of $\mathrm{HCl}$, $\mathrm{HF}, \mathrm{CCl}_{3} \mathrm{~F}$, and $\mathrm{CCl}_{2} \mathrm{~F}_{2}$ using space-, balloon- and ground-based instrument observations, Atmos. Chem. Phys., 8, 6199-6221, doi:10.5194/acp-8-6199-2008, 2008.

Manney, G. L., Zurek, R. W., O’Neill, A., and Swinbank, R.: On the motion of air through the stratospheric polar vortex, J. Atmos. Sci., 51, 2973-2994, 1994.

Manney, G. L., Daffer, W. H., Zawodny, J. M., Bernath, P. F., Hoppel, K. W., Walker, K. A., Knosp, B. W., Boone, C., Remsberg, E. E., Santee, M. L., Lynn Harvey, V., Pawson, S., Jackson, D. R., Deaver, L., McElroy, C. T., McLinden, C. A., Drummond, J. R., Pumphrey, H. C., Lambert, A., Schwartz, M. J., Froidevaux, L., McLeod, S., Takacs, L. L., Suarez, M. J., Trepte, C. R., Cuddy, D. C., Livesey, N. J., Harwood, R. S., and Waters, J. W.: Solar occultation satellite data and derived meteorological products: sampling issues and comparisons with Aura Microwave Limb Sounder, J. Geophys. Res., 112, D24S50, doi:10.1029/2007JD008709, 2007.

Manney, G. L., Daffer, W. H., Strawbridge, K. B., Walker, K. A., Boone, C. D., Bernath, P. F., Kerzenmacher, T., Schwartz, M. J., Strong, K., Sica, R. J., Krger, K., Pumphrey, H. C., Lambert, A., Santee, M. L., Livesey, N. J., Remsberg, E. E., Mlynczak,
M. G., and Russell III, J. R.: The high Arctic in extreme winters: vortex, temperature, and MLS and ACE-FTS trace gas evolution, Atmos. Chem. Phys., 8, 505-522, doi:10.5194/acp-8-505-2008, 2008.

McElroy, C. T., Nowlan, C. R., Drummond, J. R., Bernath, P. F., Barton, D. V., Dufour, D. G., Midwinter, C., Hall, R. B., Ogyu, A., Ullberg, A., Wardle, D. I., Kar, J., Zou, J., Nichitiu, F., Boone, C. D., Walker, K. A., and Rowlands, N.: The ACEMAESTRO instrument on SCISAT: description, performance, and preliminary results, Appl. Opt., 46, 4341-4356, 2007.

McLinden, C. A., Haley, C. S., and Sioris, C. E.: Diurnal effects in limb scatter observations, J. Geophys. Res., 111(D14), 302, doi:10.1029/2005JD006628, 2006.

McPherson, R., Bergman, K., Kistler, R., Rasch, G., and Gordon, D.: The NMC operational global data assimilation system, Mon. Wea. Rev., 107, 1445-1461, 1979.

Meier, A., Goldman, A., Manning, P. S., Stephen, T. M., Rinsland, C. P., Jones, N. B., and Wood, S. W.: Improvements to air mass calculations for ground-based infrared measurements, J. Quant. Spectrosc. Radiat. Transfer, 83, 109-113, 2004a.

Meier, A., Toon, G. C., Rinsland, C. P., Goldman, A., and Hase, F: Spectroscopic Atlas of atmospheric microwindows in the middle infrared. 2nd Ed. IRF Technical Report 048, IRF Institute för Rymdfysik, Kiruna, 2004b.

Mellqvist, J., Galle, B., Blumenstock, T., Hase, F., Yashcov, D., Notholt, J., Sen, B., Blavier, J. F., Toon, G.C., and Chipperfield, M. P.: Ground-based FTIR observations of chlorine activation and ozone depletion inside the Arctic vortex during the winter of 1999/2000, J. Geophys. Res., 107(D20), 8263, doi:10.1029/2001JD001080, 2002.

Murphy, C., Bell, W., Woods, P., Demoulin, P., Galle, B., Mellqvist, J., Arlander, W., Notholt, J., Goldman, A., Toon, G. C., Blavier, J. F., Sen, B., Coffey, M. T., Hannigan, J. W., Mankin, W. G., Jones, N., Griffith, D., Meier, A., Blumenstock, T., Fast, H., Mittermeier, R., and Makino, Y.: Validation of NDSC measurements of ozone, reservoir compounds and dynamical tracers: Results of a series of side-by-side instrument intercomparisons, paper presented at 2001 Symposium, Network for the Detection of Stratospheric Change, Arcachon, France, 2001.

Paton-Walsh, C., Mittermeier, R. L., Bell, W., Fast, H., Jones, N. B., and Meier, A.: An Intercomparison of Ground-based Solar FTIR Measurements of Atmospheric Gases at Eureka, Canada, J. Atmos. Ocean. Techn., 25, 2028-2036, 2008.

Picone, J. M., Hedin, A. E., Drob, D. P., and Aikin, A. C.: NRLMSISE-00 empirical model of the atmosphere: statistical comparison and scientific issues, J. Geophys. Res., 107, 14681483, 2002.

Pougatchev, N. S., Connor, B. J., and Rinsland, C. P.: Infrared measurements of the ozone vertical distribution above Kitt Peak, J. Geophys. Res., 100, 16689-16698, 1995.

Randel, W., Chanin, M.-L., and Michaut, C.: Intercomparison of Middle Atmosphere Climatologies, SPARC Report No. 3, WCRP 116, WMO/TD 1142, 2002.

Rinsland, C. P., Jones, N. B., Connor, B. J., Logan, J. A., Pougatchev, N. S., Goldman, A., Murcray, F. J., Stephen, T. M., Pine, A. S., and Zande, R.: Northern and southern hemisphere ground-based infrared spectroscopic measurements of tropospheric carbon monoxide and ethane, J. Geophy. Res., 103, 28197-28217, 1998. 
Rodgers, C. D.: Characterization and error analysis of profiles retrieved from remote sounding measurements, J. Geophys. Res., 95, 5587-5595, 1990.

Rodgers, C. D., Inverse methods for atmospheric sounding: Theory and practice, World Scientific, Singapore, 2000.

Rodgers, C. D. and Connor, B. J.: Intercomparison of remote sounding instruments, J. Geophys. Res., 108, 4116, doi:10.1029/2002JD002299, 2003.

Rothman, L. S., Jacquemart, D., Barbe, A., Benner, C., Birk, M., Brown, L. R., Carleer, M. R., Chackerian, Jr. C., Chance, K., Coudert, L. H., Dana, V., Devi, V. M., Flaud, J. M., Gamache, R. R., Goldman, A., Hartmann, J. M., Jucks, K. W., Maki, A. G., Mandin, J. Y., Massie, S. T., Orphal, J., Perrin, A., Rinsland, C. P., Smith, M. A. H., Tennyson, J., Tolchenov, R. N., Toth, R. A., Vander, J., Varanasi, P., and Wagner, G.: The HITRAN 2004 molecular spectroscopic database, J. Quant. Spectrosc. Rad. Transfer, 96, 139-204, 2005.

Russell III, J. M., Gordley, L. L., Deaver, L. E., Thompson, R. E., and Park, J. H.: An overview of the Halogen Occultation Experiment (HALOE) and preliminary results, Adv. Space Res., 14, 13-20, 1994.

Santee, M. L., MacKenzie, I. A., Manney, G. L., Chipperfield, M. P., Bernath, P. F., Walker, K. A., Boone, C. D., Froidevaux, L., Livesey, N. J., and Waters, J. W.: A study of stratospheric chlorine partitioning based on new satellite measurements and modeling, J. Geophys. Res., 113, D12307, doi:10.1029/2007JD009057, 2008.

Sinnott, R. W.: Virtues of the Haversine, Sky And Telescope, 68, 159-159, 1984.

Solomon, S.: Stratospheric ozone depletion: a review of concepts and history, Rev. Geophys., 37, 275-315, 1999.

Strong, K., Wolff, M. A., Kerzenmacher, T. E., Walker, K. A., Bernath, P. F., Blumenstock, T., Boone, C., Catoire, V., Coffey, M., De Mazière, M., Demoulin, P., Duchatelet, P., Dupuy, E., Hannigan, J., Höpfner, M., Glatthor, N., Griffith, D. W. T., Jin, J. J., Jones, N., Jucks, K., Kuellmann, H., Kuttippurath, J., Lambert, A., Mahieu, E., McConnell, J. C., Mellqvist, J., Mikuteit, S., Murtagh, D. P., Notholt, J., Piccolo, C., Raspollini, P., Ridolfi, M., Robert, C., Schneider, M., Schrems, O., Semeniuk, K., Senten, C., Stiller, G. P., Strandberg, A., Taylor, J., Tétard, C., Toohey, M., Urban, J., Warneke, T., and Wood, S.: Validation of ACE-FTS $\mathrm{N}_{2} \mathrm{O}$ measurements, Atmos. Chem. Phys., 8, 47594786, doi:10.5194/acp-8-4759-2008, 2008.

Sung, K., Skelton, R., Walker, K. A., Boone, C. D., Fu, D., and Bernath, P. F.: $\mathrm{N}_{2} \mathrm{O}$ and $\mathrm{O}_{3}$ arctic column amounts from PARISIR observations: Retrievals, characterization and error analysis, J. Quant. Spectrosc. Radiat. Transfer, 107, 385-406, 2007.

Sung, K., Strong, K., Mittermeier, R. L., Walker, K. A., Fu, D., Kerzenmacher, T., Fast, H., Bernath, P. F., Boone, C. D., Daffer, W. H., Drummond, J. R., Kolonjari, F., Loewen, P., MacQuarrie, K., and Manney, G. L.: Ground-based column measurements at Eureka, Nunavut made with two FT-IR spectrometers in spring 2004 and 2005, and comparisons with the ACE-FTS, to be submitted to Atmos. Chem. Phys., 2011.
Sussmann, R., Stremme, W., Burrows, J. P., Richter, A., Seiler, W., and Rettinger, M.: Stratospheric and tropospheric $\mathrm{NO}_{2}$ variability on the diurnal and annual scale: a combined retrieval from ENVISAT/SCIAMACHY and solar FTIR at the Permanent Ground-Truthing Facility Zugspitze/Garmisch, Atmos. Chem. Phys., 5, 2657-2677, doi:10.5194/acp-5-2657-2005, 2005.

Tarasick, D. W., Fioletov, V. E., Wardle, D. I., Kerr J. B., and Davies, J.: Changes in the vertical distribution of ozone over Canada from ozonesondes: 1980-2001, J. Geophys. Res., 110, 385-406, 2005.

Toon, G. C., Sen, B., Salawitch, R., Osterman, G., and Notholt, J.: Ground-based observations of Arctic $\mathrm{O}_{3}$ loss during spring and summer 1997, J. Geophys. Res., 104, 26497-26510, 1999.

Vigouroux, C., De Mazire, M., Errera, Q., Chabrillat, S., Mahieu, E., Duchatelet, P., Wood, S., Smale, D., Mikuteit, S., Blumenstock, T., Hase, F., and Jones, N.: Comparisons between groundbased FTIR and MIPAS $\mathrm{N}_{2} \mathrm{O}$ and $\mathrm{HNO}_{3}$ profiles before and after assimilation in BASCOE, Atmos. Chem. Phys., 7, 377-396, doi:10.5194/acp-7-377-2007, 2007.

Walker, K. A., Randall, C. E., Trepte, C. R., Boone, C. D., and Bernath, P. F.: Initial validation comparisons for the Atmospheric Chemistry Experiment (ACE-FTS), Geophys. Res. Lett., 32, L16S04, doi:10.1029/2005GL022388, 2005.

Wetzel, G., Bracher, A., Funke, B., Goutail, F., Hendrick, F., Lambert, J.-C., Mikuteit, S., Piccolo, C., Pirre, M., Bazureau, A., Belotti, C., Blumenstock, T., De Mazière, M., Fischer, H., Huret, N., Ionov, D., López-Puertas, M., Maucher, G., Oelhaf, H., Pommereau, J.-P., Ruhnke, R., Sinnhuber, M., Stiller, G., Van Roozendael, M., and Zhang, G.: Validation of MIPASENVISAT NO2 operational data, Atmos. Chem. Phys., 7, 32613284, doi:10.5194/acp-7-3261-2007, 2007.

Wiacek, A., Jones, N. B., Strong, K., Taylor, J. R., Mittermeier, R. L., and Fast, H.: First Detection of MesoThermospheric Nitric Oxide (NO) by Ground-Based FTIR Solar Absorption Spectroscopy, Geophys. Res. Lett., 33, L03811, doi:10.1029/2005GL024897, 2006.

Wolff, M. A., Kerzenmacher, T., Strong, K., Walker, K. A., Toohey, M., Dupuy, E., Bernath, P. F., Boone, C. D., Brohede, S., Catoire, V., von Clarmann, T., Coffey, M., Daffer, W. H., De Mazière, M., Duchatelet, P., Glatthor, N., Griffith, D. W. T., Hannigan, J., Hase, F., Hpfner, M., Huret, N., Jones, N., Jucks, K., Kagawa, A., Kasai, Y., Kramer, I., Küllmann, H., Kuttippurath, J., Mahieu, E., Manney, G., McElroy, C. T., McLinden, C., Mébarki, Y., Mikuteit, S., Murtagh, D., Piccolo, C., Raspollini, P., Ridolfi, M., Ruhnke, R., Santee, M., Senten, C., Smale, D., Tétard, C., Urban, J., and Wood, S.: Validation of $\mathrm{HNO}_{3}, \mathrm{ClONO}_{2}$, and $\mathrm{N}_{2} \mathrm{O}_{5}$ from the Atmospheric Chemistry Experiment Fourier Transform Spectrometer (ACE-FTS), Atmos. Chem. Phys., 8, 3529-3562, doi:10.5194/acp-8-3529-2008, 2008.

Wunch, D., Taylor, J. R., Fu, D., Bernath, P., Drummond, J. R., Midwinter, C., Strong, K., and Walker, K. A.: Simultaneous ground-based observations of $\mathrm{O}_{3}, \mathrm{HCl}, \mathrm{N}_{2} \mathrm{O}$, and $\mathrm{CH}_{4}$ over Toronto, Canada by three Fourier transform spectrometers with different resolutions, Atmos. Chem. Phys., 7, 1275-1292, doi:10.5194/acp-7-1275-2007, 2007. 